\title{
An Empirical Model of Wage Dispersion with Sorting
}

\author{
Jesper Bagger \\ University of Aarhus
}

\author{
Rasmus Lentz \\ University of Wisconsin-Madison
}

March 2007

This version: December 31, 2008

Preliminary

\begin{abstract}
The paper studies sources of wage dispersion in a model that allows for sorting in firm-worker matches. The model is a general equilibrium on-the-job search model with wage formation similar to that of Cahuc, Postel-Vinay, and Robin (2006). Workers differ in their permanent skill level and firms differ with respect to productivity. As shown in Lentz (2007), in this setting, positive (negative) sorting results if the match production function is supermodular (submodular). If the production function is modular, no sorting obtains. We propose an identification strategy that allows identification of not only the presence of sorting in matching, but also the type of sorting, negative or positive. Like Eeckhout and Kircher (2008) we find that the commonly used wage decomposition in Abowd, Kramarz, and Margolis (1999) does not in itself identify sorting, although the mechanisms that lead to lack of identification in our model differ from that of the partnership model studied in Eeckhout and Kircher (2008).
\end{abstract}




\section{Introduction}

Recent evidence suggests that worker skill and firm productivity heterogeneity are both important contributions to dispersion in observed wages. ${ }^{1}$ It is also a well documented fact that at any point in time the labor market is characterized by a large amount of worker reallocation through job transitions where workers are chasing higher wages by moving away from jobs with lower wages into jobs with higher wages. ${ }^{2}$ Hence, by its role in directing labor flows, one can view wage dispersion as a central component of the labor market's allocation mechanism. Therefore, the study of wage dispersion must include an understanding of the actual allocation of workers to firms that the labor market is implementing. In particular, this includes the issue of sorting.

Sorting may play an important role as a source of wage dispersion. Clearly, a given distribution of worker and firm types can produce very different output and wage distribution outcomes depending on how matches are formed. Previous work on the estimation of sources of wage dispersion in Abowd, Kramarz, and Margolis (1999), Postel-Vinay and Robin (2002), and Cahuc, Postel-Vinay, and Robin (2006) has adopted the maintained and identifying assumption that match formation is independent of the types of the agents involved. The analysis of Abowd, Kramarz, and Margolis (1999) directly estimates individual worker and firm fixed effects. Subsequent to the estimation the authors test whether the estimated fixed effects are correlated in the data and find little correlation. This has been taken as evidence that sorting is not an important issue in the labor market. It is however problematic to test the hypothesis of sorting within a framework where the maintained identifying assumptions rule out key mechanisms that can produce sorting in models with production function complementarities.

This paper puts forth a general equilibrium on-the-job search model with both firm and worker heterogeneity. The analysis is based on an off-the-shelf model of on-the-job search with endogenous search intensity as in Christensen, Lentz, Mortensen, Neumann, and Werwatz (2005) combined with wage determination as in Cahuc, Postel-Vinay, and Robin (2006). The model is analyzed in detail in Lentz (2007). Depending on the production function, the worker's search intensity can

\footnotetext{
${ }^{1}$ See for example Postel-Vinay and Robin (2002) and Abowd, Kramarz, and Margolis (1999).

${ }^{2}$ See for example Christensen, Lentz, Mortensen, Neumann, and Werwatz (2005), Nagypál (2005), and Jolivet, Postel-Vinay, and Robin (2006).
} 
be type dependent and sorting will result. The subsequent empirical analysis will decompose wage dispersion into 4 sources; worker heterogeneity, firm heterogeneity, friction, and sorting. PostelVinay and Robin (2002) decompose dispersion into the first three components. ${ }^{3}$

Abowd, Kramarz, and Margolis (1999) perform a decomposition of observed wage dispersion in French matched employer-employee data into unobserved worker and firm fixed effects. The panel structure of such data sets allows the continued observation of a single worker matched with different employers which is the basis of identification of individual fixed effects. The identification of the fixed effects is done under the maintained assumption that job transitions are not correlated with either worker or firm fixed effects. This precludes natural sorting mechanisms in job transition models.

Postel-Vinay and Robin (2002) and Cahuc, Postel-Vinay, and Robin (2006) make the point that the identification of unobserved fixed effects in Abowd, Kramarz, and Margolis (1999) can be biased in the presence of frictions. Specifically, the contribution of worker fixed effect dispersion to overall wage dispersion can be upward biased if the estimation does not specifically control for the particular properties of the wage process in an on-the-job search model. In these papers, wage dispersion is explained through a structural estimation of a general equilibrium on-the-job search model. Friction is given a role separate from dispersion in worker and firm effects in the explanation of overall wage dispersion. Both of the papers assume that the distribution of worker types is independent of the type of the firm. The production function in these papers is supermodular. However, the matching technology is assumed such that sorting does not arise. This paper proposes a search technology where sorting can arise in response to production function complementarities. The theoretical aspects of the model are described in greater detail in Lentz (2007).

\section{Model}

The framework of the model is an endogenous search intensity model with type heterogeneity on both the worker and firm side. The paper adopts the wage determination mechanisms of Cahuc, Postel-Vinay, and Robin (2006).

\footnotetext{
${ }^{3}$ Lise, Meghir, and Robin (2008) and Melo (2008) both study wage dispersion and sorting in a Shimer and Smith (2000) style partnership model.
} 
There is a continuum of firms and potential entrants with measure $\mathrm{m}$, and a continuum of workers with measure normalized at unity. A worker is characterized by his or her permanent innate ability $h$ which is independently and identically distributed across workers according to the cumulative distribution function $\Psi(\cdot)$. Firms differ with respect to their permanent productivity realization $p$ which is independently and identically distributed across firms according to the cumulative distribution function $\Phi(\cdot)$.

Workers can be either employed or unemployed. Regardless of employment state, a worker can search for a new job. The analysis will allow that the search technology may differ across the two employment states. Specifically, a search intensity $s$ results in the arrival rate of new job opportunities of $(\mu+\kappa s) \lambda(\theta)$ or $s \lambda(\theta)$ if unemployed or employed, respectively, where $\kappa>0$. If $\kappa>1$ then search is more efficient in the unemployed state. $\mu \geq 0$ represents an arrival of offers that is unrelated to the search decision of the worker. $\lambda(\theta)$ is the equilibrium arrival rate of offers per search unit and $\theta$ is market tightness. By assumption $\lambda^{\prime}(\theta) \geq 0$. The cost of a search intensity $s$ is given by the increasing and convex function,

$$
c(s)=\frac{c_{0} s^{1+\frac{1}{c_{1}}}}{1+\frac{1}{c_{1}}},
$$

where $c_{0}>0$ is a scale parameter and $c_{1}>0$ sets curvature.

A match between a type $h$ worker and a type $p$ firm produces value added $f(p, h)$ net of payments to capital inputs. It is assumed that $f_{p}(h, p) \geq 0$ and $f_{h}(h, p) \geq 0$ for all $(h, p)$. Hence, more skilled workers enjoy an absolute advantage relative to less skilled workers regardless of the firm type $p$ they are matched with. Likewise for the ranking of firms. Hence, the labels by which types are indexed, $h$ and $p$, define unambiguous rankings such that a high $h$ indicates a placement in the top of the worker skill ranking and a high $p$ value indicates a top placement in the firm productivity ranking. Statements on sorting then become statements about match allocation patterns in terms of worker skill and firm productivity rankings. We adopt the particular production function specification,

$$
f(h, p)=f_{0}\left(\alpha h^{\rho}+(1-\alpha) p^{\rho}\right)^{\frac{1}{\rho}}
$$

where $f_{0}$ is a scale parameter, and $0 \leq \alpha \leq 1$. If $\rho<1$, then the production function is supermodular. It is submodular for $\rho>1$. The production function is modular for $\rho=1$. As shown in 
Lentz (2007) if the production function is supermodular, the equilibrium will be characterized by positive sorting between worker skill and firm productivity. If it is submodular, negative sorting will result. For $\rho=1$ there will be no sorting between worker skill and firm productivity types.

For the sake of simplicity, the capital share is assumed constant across matches. Hence, the capital cost for a given match is $K(p, h)=k f(h, p)$, where $0 \leq k<1$. Therefore, the capital share is $k /(1+k)$. In the following analysis of match formation, values are stated in terms of the surplus net of capital costs.

Match separation occurs as the result of one of three distinct events. First, the worker in the match may receive an offer from an outside firm with greater productivity than the current firm which induces a quit. Second, at rate $\delta_{0} \lambda(\theta)$ the worker makes a job-to-job transition where the new job is drawn randomly from the vacancy offer distribution and the outside option in the new job is unemployment. The process is meant to capture that a substantial number of job-to-job transitions are observably not up the offer ladder. ${ }^{4}$ One possible explanation is that a, to the econometrician, unobserved shock has reduced the worker's valuation of the current match which induces a job-to-job transition. Nagypál (2005) provides an explicit argument for such a process. It may also be that the worker has been given notice of a lay-off sufficiently far in advance that the worker was able to obtain a new job without an actual unemployment spell in between. The model does not take an explicit stand on the exact source of the shock. It simply allows that exogenous match separations can occur where the worker's climb up the offer ladder is reset but without the association of an actual unemployment spell. Third, at exogenous rate $\delta_{1}$ the match is destroyed and the worker moves into unemployment.

Employment contracts between workers and employers are set through a Rubinstein (1982) style bargaining game following the same protocol as in Cahuc, Postel-Vinay, and Robin (2006). An alternative bargaining protocol is presented in Yamaguchi (2006). In both cases, it is assumed that the worker can use a contact with one employer as a threat point in a bargaining game with another. An employment contract can only be re-negotiated by mutual consent. If the worker is unemployed, then the value of unemployment will be the worker's threat point. The detailed

\footnotetext{
${ }^{4}$ Christensen, Lentz, Mortensen, Neumann, and Werwatz (2005) and Nagypál (2005) emphasize that this type of separation shock is empirically important.
} 
bargaining argument is presented in the appendix.

An employment contract consists of a worker's wage level and search intensity. Specifically, this implies the assumption that search intensities can be contracted upon. In the current setting this assumption implements the jointly efficient search intensity level. In the alternative case where search intensities are chosen by the worker in response to some match surplus split, the worker's search intensity will be inefficiently high in the case where the worker is not receiving the full surplus of the match. As such, one can think of the setup in this paper as describing an upper bound on the efficiency of search in the model.

Denote by $\tilde{V}(h, p, w, s)$ a type $h$ worker's asset value of a job with a type $p$ firm and employment contract $(w, s)$. The outcome of the employment contract bargaining as described in the appendix is such that the agreed upon search intensity maximizes the joint surplus of the match and the wage then dictates the surplus split. Hence, the search intensity depends only on the $(h, p)$ pair,

$$
s(h, p)=\arg \max _{s \geq 0} \tilde{V}(h, p, f(h, p), s)
$$

If the worker is unemployed, the outside option in the bargaining is the value of unemployment. Denote by $\left(w_{0}(h, p), s(h, p)\right)$ the employment contract of a type $h$ worker who was hired out of unemployment by a type $p$ firm. It satisfies,

$$
\tilde{V}\left(h, w_{0}(h, p), p, s(h, p)\right)=\beta \tilde{V}(h, f(h, p), p, s(h, p))+(1-\beta) V_{0}(h),
$$

where $V_{0}(h)$ is the asset value of unemployment for a type $h$ worker. $\beta$ is the worker's bargaining power.

If an employed worker receives an outside offer, the worker will go to the most productive firm and the outcome is as if the worker bargains with the most productive firm with a threat point of going to the less productivity firm and receive full surplus. Denote by $p$ and $q$ the types of the two firms, where $p \geq q$. If the two firms are of equal productivity, the worker stays with the current firm. Denote the resulting wage by $w(h, q, p)$. It satisfies,

$$
\tilde{V}(h, p, w(h, q, p), s(h, p))=\beta \tilde{V}(h, p, f(h, p), s(h, p))+(1-\beta) \tilde{V}(h, q, f(h, q), s(h, q)) .
$$

Denote by $q(h, p, w)$ the highest type a worker who is currently employed by a type $p$ firm at wage $w$ such that the meeting has no impact on the current employment terms. It is defined 
implicitly by,

$$
w=w(h, p, q(h, p, w))
$$

This implies that,

$$
\tilde{V}(h, p, w, s(h, p))=\beta \tilde{V}(h, p, f(h, p), s(h, p))+(1-\beta) \tilde{V}(h, q, f(h, q), s(h, q))
$$

where $q=q(h, p, w)$. Equation (6) also illustrates that any arbitrary wage received in a match with a type $p$ firm can be viewed as the outcome of bargaining with the type $p$ firm given the outside option to match with a type $q(h, p, w)$ firm. Hence, a sufficient statistic for an employed worker's state is the record of the types of the two most productive employers that the worker has met during the past employment spell. Mostly, the value functions in the following will be stated in these terms rather than through an explicit wage. Specifically define $V(h, q, p)=\tilde{V}(h, p, w(h, q, p), s(h, p))$.

It is assumed that an unemployed type $h$ worker receives an income stream $f(h, b)$. The Bellman equation for the value of unemployment is given by,

$$
\begin{aligned}
r V_{0}(h) & =\max _{s \geq 0}\left\{f(h, b)-c(s)+(\mu+\kappa s) \lambda(\theta) E\left[\max \left[0, \tilde{V}\left(h, w_{0}(h, p), p\right)-V_{0}(h)\right]\right]\right\} \\
& =\max _{s \geq 0}\left\{f(h, b)-c(s)+(\mu+\kappa s) \lambda(\theta) \int_{R(h)}^{\bar{p}} \beta\left[V\left(h, p^{\prime}, p^{\prime}\right)-V_{0}(h)\right] d \Gamma\left(p^{\prime}\right)\right\}
\end{aligned}
$$

where $r$ is the interest rate, $\Gamma(p)$ is the cumulative firm type vacancy distribution, and $R(h)$ is the type $h$ reservation productivity level defined by,

$$
V(h, R(h), R(h))=V_{0}(h)
$$

It is straightforward to prove that $V(h, p, p)$ is monotonically increasing in $p$ which establishes the reservation property of the model; that a type $h$ worker will agree to match with any employer above the productivity threshold level, $R(h)$. Applying integration by parts and the envelope theorem, equation (8) can be restated as,

$$
r V_{0}(h)=\max _{s \geq 0}\left\{f(h, b)-c(s)+(\mu+\kappa s) \lambda(\theta) \int_{R(h)}^{\bar{p}} \frac{\beta f_{p}^{\prime}\left(h, p^{\prime}\right)\left[1-\Gamma\left(p^{\prime}\right)\right] d p^{\prime}}{r+\delta+\beta s\left(h, p^{\prime}\right) \lambda(\theta)\left[1-\Gamma\left(p^{\prime}\right)\right]}\right\},
$$

where $\delta \equiv \delta_{0} \lambda(\theta)+\delta_{1}$. 
The value of employment with a type $p$ firm at wage $w(h, q, p)$ and search intensity $s(h, p)$ is given by,

$$
\begin{aligned}
r V(h, q, p)= & w(h, q, p)-c(s(h, p))+\delta_{1}\left[V_{0}(h)-V(h, q, p)\right]+ \\
& s(h, p) \lambda(\theta)\left[\int_{p}^{\bar{p}}\left[V\left(h, p, p^{\prime}\right)-V(h, q, p)\right] d \Gamma\left(p^{\prime}\right)+\int_{q}^{p}\left[V\left(h, p^{\prime}, p\right)-V(h, q, p)\right] d \Gamma\left(p^{\prime}\right)\right]+ \\
& \delta_{0} \lambda(\theta)\left[\Gamma(R(h)) V_{0}(h)+\int_{R(h)}^{\bar{p}} V\left(h, R(h), p^{\prime}\right) d \Gamma\left(p^{\prime}\right)-V(h, q, p)\right] .
\end{aligned}
$$

Integration by parts and the envelope theorem allows the expression to be re-written as,

$$
\begin{aligned}
(r+\delta) V(h, q, p)= & w(h, q, p)-c(s(h, p))+\delta V_{0}(h)+\delta_{0} \lambda(\theta) \int_{R(h)}^{\bar{p}} \frac{\beta f_{p}\left(h, p^{\prime}\right)\left(1-\Gamma\left(p^{\prime}\right)\right) d p^{\prime}}{r+\delta s\left(h, p^{\prime}\right) \lambda(\theta)\left(1-\Gamma\left(p^{\prime}\right)\right)}+ \\
& s(h, p) \lambda(\theta) \int_{p}^{\bar{p}} \frac{\beta f_{p}\left(h, p^{\prime}\right)\left(1-\Gamma\left(p^{\prime}\right)\right) d p^{\prime}}{r+\delta+\beta s\left(h, p^{\prime}\right) \lambda(\theta)\left(1-\Gamma\left(p^{\prime}\right)\right)}+ \\
& s(h, p) \lambda(\theta) \int_{q}^{p} \frac{(1-\beta) f_{p}\left(h, p^{\prime}\right)\left(1-\Gamma\left(p^{\prime}\right)\right) d p^{\prime}}{r+\delta+\beta s\left(h, p^{\prime}\right) \lambda(\theta)\left(1-\Gamma\left(p^{\prime}\right)\right)} .
\end{aligned}
$$

The detailed derivation of equation (12) can be found in the appendix.

\subsection{The search choices}

The employment state conditional search intensity is found by use of equations (3) and (8). Together with equation (12), they imply the first order conditions,

$$
\begin{aligned}
c^{\prime}\left(s_{0}(h)\right) & =\kappa \lambda(\theta) \int_{R(h)}^{\bar{p}} \frac{\beta f_{p}\left(h, p^{\prime}\right)\left(1-\Gamma\left(p^{\prime}\right)\right) d p^{\prime}}{r+\delta+\beta s\left(h, p^{\prime}\right) \lambda(\theta)\left(1-\Gamma\left(p^{\prime}\right)\right)} \\
c^{\prime}(s(h, p)) & =\lambda(\theta) \int_{p}^{\bar{p}} \frac{\beta f_{p}\left(h, p^{\prime}\right)\left(1-\Gamma\left(p^{\prime}\right)\right) d p^{\prime}}{r+\delta+\beta s\left(h, p^{\prime}\right)\left(1-\Gamma\left(p^{\prime}\right)\right)} .
\end{aligned}
$$

By convexity of $c(\cdot)$, differentiation of equation (14) with respect to $p$ immediately yields that $s(h, p)$ is monotonically decreasing in $p, \forall h$. Furthermore, $s(h, \bar{p})=0, \forall h$. Lemma 1 establishes that the search intensity is strictly increasing in the worker type $h$ if the production function is strictly supermodular. Also, if the production function has no complementarities between worker and firm types, then the search intensity is identical across worker types.

Lemma 1 For any pair $\left(h_{0}, h_{1}\right) \in[\underline{h}, \bar{h}] \times[\underline{h}, \bar{h}]$ such that $h_{0}<h_{1}$, and for all $p \in[b, \bar{p})$,

- $f_{h p}(h, p)>0 \forall(h, p) \Rightarrow s\left(h_{0}, p\right)<s\left(h_{1}, p\right)$ (supermodular).

- $f_{h p}(h, p)<0 \forall(h, p) \Rightarrow s\left(h_{0}, p\right)>s\left(h_{1}, p\right)$ (submodular). 
- $f_{h p}(h, p)=0 \forall(h, p) \Rightarrow s\left(h_{0}, p\right)=s\left(h_{1}, p\right)$ (modular).

For any $h \in[\underline{h}, \bar{h}], s(h, \bar{p})=0$.

Proof. See Lentz (2007)

The reservation productivity level $R(h)$ defined in equation (9) is characterized in Lemma 2

Lemma 2 For any $h \in[\underline{h}, \bar{h}]$, if $\kappa=1$ and $\mu=\delta_{0}$ then $R(h)=b$, and if $\kappa>1$ and $\mu>\delta_{0}$ then $\bar{p}>$ $R(h)>b$. Furthermore, if for any pair $\left(h_{0}, h_{1}\right) \in[\underline{h}, \bar{h}]$ and for all $p \in[b, \bar{p}] f_{p}\left(h_{0}, p\right)=f_{p}\left(h_{1}, p\right)$, then $R\left(h_{0}\right)=R\left(h_{1}\right)$.

Proof. See Lentz (2007)

In the case where $\kappa>1$, an obvious question of interest is how $R(h)$ varies with $h$. Lemma 2 states that in the absence of production function complementarities, $R(h)$ is identical across worker types. If $\rho \neq 1$ the model includes many of the complications associated with the classic stopping problem as analyzed in Shimer and Smith (2000). Specifically, it is straightforward to produce examples where $R(h)$ is not monotonically increasing in $h$ even if the production function is supermodular.

\subsection{Solving for the wage}

With a solution for $s(h, p)$ in hand, one can immediately obtain values for the Bellman equation for the following states,

$$
\begin{aligned}
(r+\delta) V(h, p, p)= & f(h, p)-c(s(h, p))+\delta V_{0}(h)+\delta_{0} \lambda(\theta) \int_{R(h)}^{\bar{p}} \frac{\beta f_{p}\left(h, p^{\prime}\right)\left(1-\Gamma\left(p^{\prime}\right)\right) d p^{\prime}}{r+\delta+\beta s\left(h, p^{\prime}\right) \lambda(\theta)\left(1-\Gamma\left(p^{\prime}\right)\right)}+ \\
& s(h, p) \lambda(\theta) \int_{p}^{\bar{p}} \frac{\beta f_{p}\left(h, p^{\prime}\right)\left(1-\Gamma\left(p^{\prime}\right)\right) d p^{\prime}}{r+\delta+\beta s\left(h, p^{\prime}\right) \lambda(\theta)\left(1-\Gamma\left(p^{\prime}\right)\right)}, \forall p \geq b .
\end{aligned}
$$

The value of the unemployed state is,

$$
r V_{0}(h)=f(h, b)-c\left(s_{0}(h)\right)+\left(\mu+\kappa s_{0}(h)\right) \lambda(\theta) \int_{R(h)}^{\bar{p}} \frac{\beta f_{p}\left(h, p^{\prime}\right)\left(1-\Gamma\left(p^{\prime}\right)\right) d p^{\prime}}{r+\delta+\beta s\left(h, p^{\prime}\right) \lambda(\theta)\left(1-\Gamma\left(p^{\prime}\right)\right)} .
$$

Given the wage determination mechanism in equation (5) combined with equation (15), one obtains,

$$
V(h, q, p)=\beta V(h, p, p)+(1-\beta) V(h, q, q) .
$$


It then directly follows from equation (12) that,

$$
\begin{aligned}
w(h, q, p)= & (r+\delta) V(h, q, p)+c(s(h, p))-\delta V_{0}(h)-\delta_{0} \lambda(\theta) \int_{R(h)}^{\bar{p}} \frac{\beta f_{p}\left(h, p^{\prime}\right)\left(1-\Gamma\left(p^{\prime}\right)\right) d p^{\prime}}{r+\delta+\beta s\left(h, p^{\prime}\right) \lambda(\theta)\left(1-\Gamma\left(p^{\prime}\right)\right)}- \\
& s(h, p) \lambda(\theta)\left[\int_{p}^{\bar{p}} \frac{\beta f_{p}\left(h, p^{\prime}\right)\left(1-\Gamma\left(p^{\prime}\right)\right) d p^{\prime}}{r+\delta+\beta s\left(h, p^{\prime}\right) \lambda(\theta)\left(1-\Gamma\left(p^{\prime}\right)\right)}+\int_{q}^{p} \frac{(1-\beta) f_{p}\left(h, p^{\prime}\right)\left(1-\Gamma\left(p^{\prime}\right)\right) d p^{\prime}}{r+\delta+\beta s\left(h, p^{\prime}\right) \lambda(\theta)\left(1-\Gamma\left(p^{\prime}\right)\right)}\right]
\end{aligned}
$$

\subsection{Vacancy creation}

Each firm is characterized by a permanent productivity $p$ that applies to all of its matches. Firm types are distributed according to the cumulative distribution function $\Phi(\cdot)$. A firm's total output is the sum of the output of all its matches. Hence, a firm with $n$ workers produces,

$$
Y\left(h^{n}, p\right)=\sum_{i=1}^{n} f\left(h_{i}, p\right)
$$

The total wage bill of the firm depends not only on the vector of worker types, but also on the next best offer of each worker.

At any given time, each firm chooses a vacancy intensity $\nu$ at $\operatorname{cost} c_{\nu}(\nu)$, where $c_{\nu}(\cdot)$ is strictly increasing and convex. Given the choice of vacancy intensity, the firm meets a new worker at rate $\eta \nu$. If a productivity $p$ firm meets a skill $h$ worker currently matched with a productivity $p^{\prime}<p$ firm, the worker will accept to match with the productivity $p$ firm. The bargaining will award value $V\left(h, p^{\prime}, p\right)$ to the worker and the firm will receive value $V(h, p, p)-V\left(h, p^{\prime}, p\right)$, which is the full match surplus minus the worker's share. The vacancy intensity choice is made so as to maximize the value of the firm's hiring operation,

$$
J_{0}(p)=\max _{\nu \geq 0}\left[-c_{\nu}(\nu)+\eta \nu \int_{\underline{h}}^{\bar{h}} \int_{R\left(h^{\prime}\right)}^{p}\left[V\left(h^{\prime}, p, p\right)-V\left(h^{\prime}, p^{\prime}, p\right)\right] d \Lambda\left(h^{\prime}, p^{\prime}\right)\right]
$$

where

$$
\Lambda(h, p)=\frac{\int_{\underline{h}}^{h}\left\{\frac{u}{1-u}\left[\mu+\kappa s_{0}\left(h^{\prime}\right)\right] v\left(h^{\prime}\right)+\delta_{0} \int_{b}^{\bar{p}} g\left(h^{\prime}, p^{\prime}\right) d p^{\prime}+\int_{b}^{p} s\left(h^{\prime}, p^{\prime}\right) g\left(h^{\prime}, p^{\prime}\right) d p^{\prime}\right\} d h^{\prime}}{\int_{\underline{h}}^{\bar{h}}\left\{\frac{u}{1-u}\left[\mu+\kappa s_{0}\left(h^{\prime}\right)\right] v\left(h^{\prime}\right)+\int_{b}^{\bar{p}}\left[\delta_{0}+s\left(h^{\prime}, p^{\prime}\right)\right] g\left(h^{\prime}, p^{\prime}\right) d p^{\prime}\right\} d h^{\prime}}
$$

is the cumulative distribution function of searching workers by skill level and productivity of the firm in the current match. For the purpose of the definition of $\Lambda$, unemployment is considered as a match at the reservation level. The expression reflects a proportionality assumption in matching; a worker is represented in the pool of searchers proportionally to his or her search intensity. $g(h, p)=$ 
$\int_{b}^{p} g(h, q, p) d q$ is the density of matches between skill $h$ workers and productivity $p$ firms, where $g(h, q, p)$ is the joint pdf of matches. $u$ is the unemployment rate and $\Upsilon(h)$ is the CDF of worker skill in the unemployment pool.

It follows from equation (19) that the first order condition on the productivity conditional vacancy intensity choice is,

$$
c_{\nu}^{\prime}(\nu(p))=\eta(1-\beta) \int_{\underline{h}}^{\bar{h}} \int_{R\left(h^{\prime}\right)}^{p}\left[V\left(h^{\prime}, p, p\right)-V\left(h^{\prime}, p^{\prime}, p^{\prime}\right)\right] d \Lambda\left(h^{\prime}, p^{\prime}\right) .
$$

A firm's hiring rate is the product of the meeting rate and the probability that the worker in question accepts the firm's offer,

$$
\eta(p)=\eta \nu(p) \int_{\underline{h}}^{\bar{h}} I\left(R\left(h^{\prime}\right) \leq p\right) d \Lambda\left(h^{\prime}, p\right) .
$$

The expected match separation rate for a type $p$ firm is given by,

$$
d(p)=\delta+[1-\Gamma(p)] \frac{\int_{\underline{h}}^{\bar{h}} s(h, p) g(h, p) d h}{\int_{\underline{h}}^{\bar{h}} g(h, p) d h} .
$$

\subsection{Steady state}

The steady state condition on the joint CDF of matches, $G(h, q, p)$, is,

$$
\begin{array}{r}
(1-u) \delta G(h, q, p)+(1-u) \int_{\underline{h}}^{h} \int_{R\left(h^{\prime}\right)}^{q} \lambda(\theta)\left\{(1-\Gamma(p)) \int_{q^{\prime}}^{q} s\left(h^{\prime}, p^{\prime}\right) d G\left(h^{\prime}, q^{\prime}, p^{\prime}\right)\right. \\
\left.+(1-\Gamma(q)) \int_{q}^{p} s\left(h^{\prime}, p^{\prime}\right) d G\left(h^{\prime}, q^{\prime}, p^{\prime}\right)\right\}= \\
\int_{\underline{h}}^{h} I\left(R\left(h^{\prime}\right) \leq q\right) \lambda(\theta)\left[\Gamma(p)-\Gamma\left(R\left(h^{\prime}\right)\right)\right]\left[u\left[\mu+\kappa s_{0}\left(h^{\prime}\right)\right] v\left(h^{\prime}\right)+\right. \\
\left.(1-u) \delta_{0} \int_{R\left(h^{\prime}\right)}^{\bar{p}} \int_{q^{\prime}}^{\bar{p}} g\left(h^{\prime}, q^{\prime}, p^{\prime}\right) d p^{\prime} d q^{\prime}\right] d h^{\prime},
\end{array}
$$

where $I(\cdot)$ is an indicator function that equals one if its expression is true, zero if false. The left hand side captures the flow out of the $G(h, q, p)$ mass and the right hand side is the flow in. By steady state the two flows must equal each other. Equation (23) implies that steady state unemployment satisfies,

$$
u=\left[\int_{\underline{h}}^{\bar{h}}\left(1+\frac{\left[1-\Gamma\left(R\left(h^{\prime}\right)\right)\right]\left[\mu+\kappa s_{0}\left(h^{\prime}\right)\right] \lambda(\theta)}{\delta_{0} \lambda(\theta) \Gamma\left(R\left(h^{\prime}\right)\right)+\delta_{1}}\right) d \Upsilon\left(h^{\prime}\right)\right]^{-1} .
$$


Using equation (24), one can re-write equation (23) as (see the detailed derivations in the appendix),

$$
\begin{gathered}
\int_{\underline{h}}^{h} \int_{R\left(h^{\prime}\right)}^{q}\left[\int_{q^{\prime}}^{q}\left[\delta / \lambda(\theta)+[1-\Gamma(p)] s\left(h^{\prime}, p^{\prime}\right)\right] g\left(h^{\prime}, q^{\prime}, p^{\prime}\right) d p^{\prime}\right. \\
\left.+\int_{q}^{p}\left[\delta / \lambda(\theta)+[1-\Gamma(q)] s\left(h^{\prime}, p^{\prime}\right)\right] g\left(h^{\prime}, q^{\prime}, p^{\prime}\right) d p^{\prime}\right] d q^{\prime} d h^{\prime}= \\
\frac{\delta}{\lambda(\theta)} \frac{\int_{\underline{h}}^{h} I\left(R\left(h^{\prime}\right) \leq q\right)\left[\Gamma(p)-\Gamma\left(R\left(h^{\prime}\right)\right)\right] \frac{\mu+\kappa s_{0}\left(h^{\prime}\right)}{\delta_{0} \Gamma\left(R\left(h^{\prime}\right)\right)+\delta_{1} / \lambda(\theta)} d \Psi\left(h^{\prime}\right)}{\int_{\underline{h}}^{\bar{h}} \frac{\left[1-\Gamma\left(R\left(h^{\prime}\right)\right)\right]\left[\mu+\kappa s_{0}\left(h^{\prime}\right)\right]}{\delta_{0} \Gamma\left(R\left(h^{\prime}\right)\right)+\delta_{1} / \lambda(\theta)} d \Psi\left(h^{\prime}\right)} .
\end{gathered}
$$

In steady state, the mass of productivity $p$ firms with $n$ workers $m_{n}(p)$ must be constant. Hence, the steady state firm size distribution satisfies,

$$
0=\eta(p) m_{n-1}(p)+d(p)(n+1) m_{n+1}(p)-(\eta(p)+d(p) n) m_{n}(p)
$$

for all $n \geq 1$ and $p$. It can be shown that the firm's expected labor force composition is independent of its size. Hence, the expected destruction rate of matches is $d(p)$ for any firm size. Also, in steady state the number of firm births must equal the number of deaths,

$$
\eta(p) m_{0}(p)=d(p) m_{1}(p) .
$$

Furthermore, it is given that

$$
\sum_{n=0}^{\infty} m_{n}(p)=m \phi(p)
$$

where $\phi(p)$ is the firm productivity distribution pdf. Equations (26)-(28) imply that the type conditional firm size distribution $m_{n}(p) /(m \phi(p))$ is Poisson with arrival rate $\eta(p) / d(p)$,

$$
m_{n}(p)=\left(\frac{\eta(p)}{d(p)}\right)^{n} \frac{1}{n !} \exp \left(-\frac{\eta(p)}{d(p)}\right) m \phi(p),
$$

for all $n \geq 0$.

\subsection{Steady state equilibrium}

The equilibrium vacancy offer distribution is given by,

$$
\Gamma(p)=\frac{\int_{b}^{p} \nu\left(p^{\prime}\right) d \Phi\left(p^{\prime}\right)}{\int_{b}^{\bar{p}} \nu\left(p^{\prime}\right) d \Phi\left(p^{\prime}\right)} .
$$

In equilibrium, the meeting rates of both workers and firms must balance which implies,

$$
\lambda(\theta)=\theta \eta(\theta),
$$


where

$$
\theta=\frac{m \int_{b}^{\bar{p}} \nu\left(p^{\prime}\right) d \Phi\left(p^{\prime}\right)}{u \int_{\underline{h}}^{\bar{h}}\left[\mu+\kappa s_{0}(h)\right] d \Upsilon(h)+(1-u) \int_{\underline{h}}^{\bar{h}} \int_{b}^{\bar{p}}\left[\delta_{0}+s(h, p)\right] d G(h, p)} .
$$

Furthermore, the overall worker type distribution is related to the employment state conditional type distributions by, $\Psi(h)=(1-u) G(h, \bar{p}, \bar{p})+u \Upsilon(h)$ which by use of the steady state conditions on $G(h, q, p)$ and $u$ produces (see detailed derivations in the appendix),

$$
\Upsilon(h)=\frac{\int_{\underline{h}}^{h} \frac{\delta_{0} \Gamma\left(R\left(h^{\prime}\right)\right)+\delta_{1} / \lambda(\theta)}{\delta_{0} \Gamma\left(R\left(h^{\prime}\right)\right)+\delta_{1} / \lambda(\theta)+\left[1-\Gamma\left(R\left(h^{\prime}\right)\right)\right]\left[\mu+\kappa s_{0}\left(h^{\prime}\right)\right]} d \Psi\left(h^{\prime}\right)}{\int_{\underline{h}}^{\bar{h}} \frac{\delta_{0} \Gamma\left(R\left(h^{\prime}\right)\right)+\delta_{1} / \lambda(\theta)}{\delta_{0} \Gamma\left(R\left(h^{\prime}\right)\right)+\delta_{1} / \lambda(\theta)+\left[1-\Gamma\left(R\left(h^{\prime}\right)\right)\right]\left[\mu+\kappa s_{0}\left(h^{\prime}\right)\right]} d \Psi\left(h^{\prime}\right)} .
$$

With these conditions, steady state equilibrium can be defined.

Definition 1 A steady state equilibrium is a tuple $\left\{G(h, q, p), \Upsilon(h), \Gamma(p), u, s(h, p), s_{0}(h), R(h), \eta\right.$, $w(h, q, p)\}$ that satisfies equations (9), (13), (14), (18), (24), (25), (30), (32), and (33).

Lentz (2007) provides proof of existence and uniqueness of equilibrium in a slightly simpler version of the model where vacancy intensities are constant across firm types.

\section{Properties of steady state equilibrium}

We will make the simplifying assumption that $\kappa=1$ and consequently $R(h)=b$ for all $h$. The steady state equilibrium may or may not display sorting depending on the characteristics of the production function. In this section, we make the simplifying assumption that $\mu=\delta 0$. Proposition 1 states sufficient conditions for positive sorting to occur. First, define the worker type conditional CDF of firm types by,

$$
\Omega_{h}(p)=\frac{\int_{b}^{p} g\left(h, p^{\prime}\right) d p^{\prime}}{\int_{b}^{\bar{p}} g\left(h, p^{\prime}\right) d p^{\prime}} .
$$

One can then state the central characterization of sorting in steady state equilibrium. ${ }^{5}$

Proposition 1 For any $h \in[\underline{h}, \bar{h}], \Omega_{h}(b)=0$ and $\Omega_{h}(\bar{p})=1$. Consider any pair $\left(h_{0}, h_{1}\right) \in$ $[\underline{h}, \bar{h}] \times[\underline{h}, \bar{h}]$ such that $h_{0}<h_{1}$. Then for all $p \in(b, \bar{p})$,

- $f_{h p}(h, p)>0 \forall(h, p) \Rightarrow \Omega_{h_{0}}(p)>\Omega_{h_{1}}(p)$ (supermodular).

- $f_{h p}(h, p)<0 \forall(h, p) \Rightarrow \Omega_{h_{0}}(p)<\Omega_{h_{1}}(p)$ (submodular).

\footnotetext{
${ }^{5}$ This proposition is given in Lentz (2007). We state it here for completeness.
} 
- $f_{h p}(h, p)=0 \forall(h, p) \Rightarrow \Omega_{h_{0}}(p)=\Omega_{h_{1}}(p)$ (modular)

Proof. See Lentz (2007).

It is worth emphasizing that the stochastic dominance results in Proposition 1 do not cleanly extend to the firm productivity conditional worker skill distribution,

$$
\Omega_{p}(h)=\frac{\int_{\underline{h}}^{h} g\left(h^{\prime}, p\right) d h^{\prime}}{\int_{\underline{h}}^{\bar{h}} g\left(h^{\prime}, p\right) d h^{\prime}} .
$$

It is possible to locally break the stochastic dominance results for this conditioning.

\section{Identification}

A key question of interest is the identification of the production function, in particular the $\rho$ coefficient which determines the sign and strength of complementarity between firm productivity and worker skill in production. In a partnership model, Eeckhout and Kircher (2008) argue that an identification strategy based on an Abowd, Kramarz, and Margolis (1999) style wage fixed effects equation fails to identify sorting. Specifically, while one can identify the strength of sorting by comparing the within firm distribution of worker fixed effects to the full population, the strategy fails to identify whether sorting is positive or negative. ${ }^{6}$ The lack of identification in the Eeckhout and Kircher (2008) setup follows from the result that even though worker skill and firm productivity map monotonically and strictly positively into match output, the match wage is not a monotone mapping in worker and firm types. This fundamentally breaks the link between estimated wage fixed effects and the identification of underlying worker and firm types.

We will argue that the Eeckhout and Kircher (2008) result can be generalized to our framework. The argument again rests on a result that wages may be non-monotone in agent types. However, it is not a trivial extension since the cause of the non-monotonicity differs substantially from that of the partnership model. The result provides some credibility to the argument that the Eeckhout and Kircher (2008) results extend significantly beyond their somewhat specialized setup. We subsequently offer an identification strategy that within our framework does identify both the strength and sign of sorting.

\footnotetext{
${ }^{6}$ Given the maintained identifying assumption of production function supermodularity, Melo (2008) identifies the strength of the positive complementarity by the correlation between worker fixed effects within the firm.
} 


\subsection{The wage function}

Abowd, Kramarz, and Margolis (1999) assume a log wage equation where worker and firm fixed effects enter additively,

$$
w_{i t}=x_{i t} \beta+\chi_{i}+\varphi_{J(i, t)}+\varepsilon_{i t},
$$

where $J(i, t)$ is the firm ID that worker $i$ is matched with at time $t, x_{i t}$ is the set of worker $i$ characteristics at time $t$, and $\chi_{i}$ and $\varphi_{j}$ are the worker and firm fixed effects. The identification of the fixed effects from matched employer-employee data relies on this additive structure. Consider a class of models where workers differ by skill and firms by productivity. An agent's type is permanent. Furthermore, match output is increasing in both skill and productivity. Can the estimated worker and firm fixed effects from the log-linear wage equation be used as the basis for identification of the underlying worker skill and firm productivity heterogeneity? In particular, does the correlation between the estimated worker and firm fixed effects, $\operatorname{cor}\left[\chi_{i}, \varphi_{J(i, t)}\right]$, identify sorting in the matching between worker skill and firm productivity? Eeckhout and Kircher (2008) provide a negative answer for their model. We will generally provide a negative answer as well. Both answers are based on the insight that for the model structures in question, the log additive wage equation is fundamentally mis-specified with respect to the worker and firm heterogeneity contributions to wages. Specifically, wages are generally not monotonically increasing in skill and productivity.

It is well known that given the wage posting setup in Postel-Vinay and Robin (2002), wages can initially decrease as a worker moves from a less to a more productive firm if the move is associated with an expectation of a higher wage growth rate. This is the key intuition for why worker skill conditional wages can be non-monotone in firm productivity in the model. Firm productivity conditional wages can furthermore also be non-monotone in worker skill as a result of differential search intensities across worker skill levels and differential returns to job offer accumulation that both map into different wage growth expectations.

It is worthwhile to contrast the wage non-monotonicity result in this model with that of the classic partnership model. In the partnership model, the non-monotonicity extends to the agent's match value functions. If for example the equilibrium is characterized by positive sorting, a high type agent tends to be matched with another high type agent in equilibrium. A low type agent may 
find that even though match output would increase by matching with a high type agent relative to another low type, the outside option of the high type is so high that the low type would have to deliver enough surplus to make the match acceptable to the high type, that the low type agent would actually prefer to match with another low type.

Our model does not exhibit this feature. Any worker regardless of skill level always prefers to match with a higher productivity firm. Furthermore, a worker would always prefer to have more skill regardless of the firm they are matched with. This result is stated in Lemma 3 . The non-monotonicity of wages in skill and productivity is a result of the feature that the productivity of today's firm impacts the growth rate of future wages which is driven by the accumulation of outside offers.

Lemma 3 The worker's valuation of a match $V(h, q, p)$ is strictly increasing in all three arguments.

Proof. By equation (17), the match value satisfies $V(h, q, p)=\beta V(h, p, p)+(1-\beta) V(h, q, q)$. For notational convenience, define $V(h, p) \equiv V(h, p, p)$. By equation (47) it is already established that $V_{p}(h, p)>0$. Hence, to establish the result in Lemma 3 , it only remains to establish that $V(h, p)$ is increasing in $h . V(h, p)$ can be written as,

$$
\begin{aligned}
r V(h, p)= & f(h, p)-c(s(h, p))+\delta_{1} V_{0}(h)+s(h, p) \lambda(\theta) \int_{p}^{\bar{p}} V\left(h, p, p^{\prime}\right) d \Gamma\left(p^{\prime}\right) \\
& +\delta_{0} \lambda(\theta) \int_{b}^{\bar{p}} V\left(h, b, p^{\prime}\right) d \Gamma\left(p^{\prime}\right)-\left[\delta_{0} \lambda(\theta)+\delta_{1}+s(h, p) \lambda(\theta)[1-\Gamma(p)]\right] V(h, p) \\
= & f(h, p)-c(s(h, p))+\left[\delta_{1}+\delta_{0} \lambda(\theta)(1-\beta)\right] V_{0}(h) \\
& +\delta_{0} \lambda(\theta) \beta \int_{b}^{\bar{p}} V\left(h, p^{\prime}\right) d \Gamma\left(p^{\prime}\right)+s(h, p) \lambda(\theta) \beta \int_{p}^{\bar{p}} V\left(h, p^{\prime}\right) d \Gamma\left(p^{\prime}\right) \\
& -\left[\delta_{0} \lambda(\theta)+\delta_{1}+\beta s(h, p) \lambda(\theta)[1-\Gamma(p)]\right] V(h, p) .
\end{aligned}
$$

By the assumption of jointly efficient search intensity, this can then be written as,

$$
\begin{aligned}
V(h, p)= & \max _{s \geq 0}\left\{\frac{f(h, p)-c(s)+\delta_{1} V_{0}(h)+\beta s \lambda(\theta) \int_{p}^{\bar{p}} V\left(h, p^{\prime}\right) d \Gamma\left(p^{\prime}\right)}{r+\delta_{0} \lambda(\theta)+\delta_{1}+\beta s \lambda(\theta)[1-\Gamma(p)]}\right. \\
& \left.+\delta_{0} \lambda(\theta) \frac{V_{0}(h)+\beta \int_{b}^{\bar{p}}\left[V\left(h, p^{\prime}\right)-V_{0}(h)\right] d \Gamma\left(p^{\prime}\right)}{r+\delta_{0} \lambda(\theta)+\delta_{1}+\beta s \lambda(\theta)[1-\Gamma(p)]}\right\},
\end{aligned}
$$

where

$$
r V_{0}(h)=\max _{s \geq 0}\left\{f(h, b)-c(s)+(\mu+s) \lambda(\theta) \beta \int_{b}^{\bar{p}}\left[V\left(h, p^{\prime}\right)-V_{0}(h)\right] d \Gamma\left(p^{\prime}\right)\right\} .
$$


It is straightforward to show that the fixed point of the mapping in equation (38) satisfies,

$$
V_{0}(h)=\max _{s \geq 0}\left\{\frac{f(h, b)-c(s)+(\mu+s) \lambda(\theta) \beta \int_{b}^{\bar{p}} V\left(h, p^{\prime}\right) d \Gamma\left(p^{\prime}\right)}{r+(\mu+s) \lambda(\theta) \beta}\right\} .
$$

This then establishes a unique solution to equation (38). Furthermore, inspection of equation (40) reveals that if $V(h, p)$ is increasing in $h$, then $V_{0}(h)$ is strictly increasing in $h$.

Equation (37) is a contraction. Denote the mapping $T: \mathcal{F} \rightarrow \mathcal{F}$, where $\mathcal{F}$ is the set of bounded, continuous functions. For the purpose of showing that $T$ maps the set of weakly increasing functions into the set of strictly increasing functions, consider any $h_{0}<h_{1}$ where both $h_{0}$ and $h_{1}$ belong to the support of worker skill types. Now, take any function $V(h, p)$ that is weakly increasing in $h$ for any $p$. Furthermore, let $s(h, p)$ be the maximizer of the right hand side of equation $(37)$ for $V(h, p)$ and any $h$ in the support of $\Psi(\cdot)$. Finally, let $V_{0}(h)$ be defined by equation (40) for the value of employment given by $V(h, p)$. It then follows that,

$$
\begin{aligned}
(T V)\left(h_{0}, p\right)= & \frac{f\left(h_{0}, p\right)-c\left(s\left(h_{0}, p\right)\right)+\delta_{1} V_{0}\left(h_{0}\right)+\beta s\left(h_{0}, p\right) \lambda(\theta) \int_{p}^{\bar{p}} V\left(h_{0}, p^{\prime}\right) d \Gamma\left(p^{\prime}\right)}{r+\delta_{0} \lambda(\theta)+\delta_{1}+\beta s\left(h_{0}, p\right) \lambda(\theta)[1-\Gamma(p)]} \\
& +\delta_{0} \lambda(\theta) \frac{V_{0}\left(h_{0}\right)+\beta \int_{b}^{\bar{p}}\left[V\left(h_{0}, p^{\prime}\right)-V_{0}\left(h_{0}\right)\right] d \Gamma\left(p^{\prime}\right)}{r+\delta_{0} \lambda(\theta)+\delta_{1}+\beta s\left(h_{0}, p\right) \lambda(\theta)[1-\Gamma(p)]} \\
< & \frac{f\left(h_{0}, p\right)-c\left(s\left(h_{0}, p\right)\right)+\delta_{1} V_{0}\left(h_{1}\right)+\beta s\left(h_{0}, p\right) \lambda(\theta) \int_{p}^{\bar{p}} V\left(h_{1}, p^{\prime}\right) d \Gamma\left(p^{\prime}\right)}{r+\delta_{0} \lambda(\theta)+\delta_{1}+\beta s\left(h_{0}, p\right) \lambda(\theta)[1-\Gamma(p)]} \\
& +\delta_{0} \lambda(\theta) \frac{V_{0}\left(h_{1}\right)+\beta \int_{b}^{\bar{p}}\left[V\left(h_{1}, p^{\prime}\right)-V_{0}\left(h_{1}\right)\right] d \Gamma\left(p^{\prime}\right)}{r+\delta_{0} \lambda(\theta)+\delta_{1}+\beta s\left(h_{0}, p\right) \lambda(\theta)[1-\Gamma(p)]} \\
\leq & \frac{f\left(h_{0}, p\right)-c\left(s\left(h_{1}, p\right)\right)+\delta_{1} V_{0}\left(h_{1}\right)+\beta s\left(h_{1}, p\right) \lambda(\theta) \int_{p}^{\bar{p}} V\left(h_{1}, p^{\prime}\right) d \Gamma\left(p^{\prime}\right)}{r+\delta_{0} \lambda(\theta)+\delta_{1}+\beta s\left(h_{1}, p\right) \lambda(\theta)[1-\Gamma(p)]} \\
& +\delta_{0} \lambda(\theta) \frac{V_{0}\left(h_{1}\right)+\beta \int_{b}^{\bar{p}}\left[V\left(h_{1}, p^{\prime}\right)-V_{0}\left(h_{1}\right)\right] d \Gamma\left(p^{\prime}\right)}{r+\delta_{0} \lambda(\theta)+\delta_{1}+\beta s\left(h_{1}, p\right) \lambda(\theta)[1-\Gamma(p)]} \\
= & (T V)\left(h_{1}, p\right),
\end{aligned}
$$

where the first inequality comes from the assumption that $V(h, p)$ is increasing in $h$. The second inequality comes from $s(h, p)$ being the optimal choice of search intensity given $(h, p)$. Hence, by the contraction mapping theorem, since $T$ maps the set of function $V(h, p)$ that are increasing in $h$ into the set of functions that are strictly increasing in $h$, it must be that the fixed point of equation (37) is strictly increasing in $h$. This establishes Lemma 3.

To illustrate the points, we simulate wages for the following model specification: Simplify vacancy creation so that $\nu(p)=1, \forall p$. The model parameters are set as follows; $c_{0}=1, c_{1}=0.5$, 
Figure 1: Skill and Productivity Conditional Wages $(\beta=0.2)$

(a) Supermodular $(\rho=-10)$

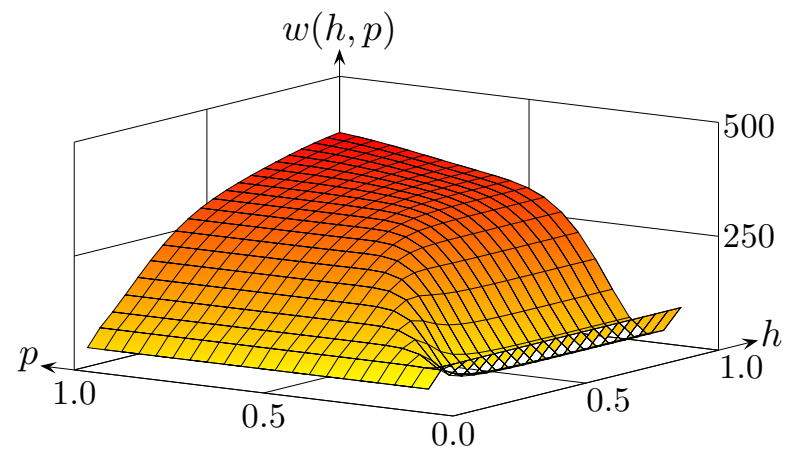

(b) Submodular $(\rho=10)$

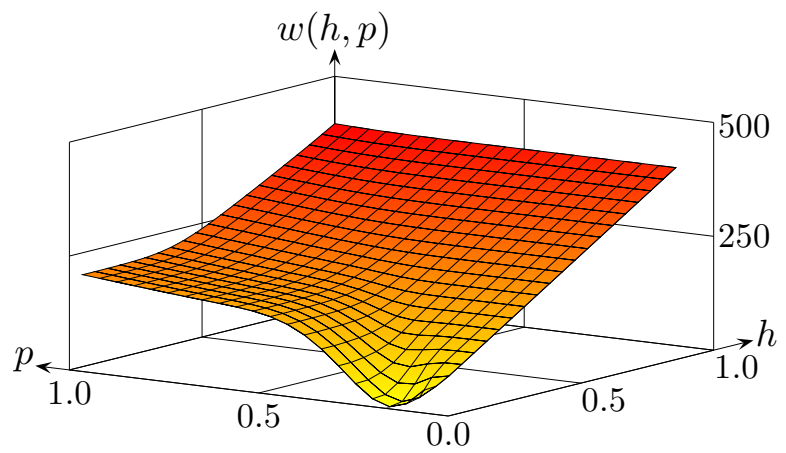

(c) Modular $(\rho=1)$

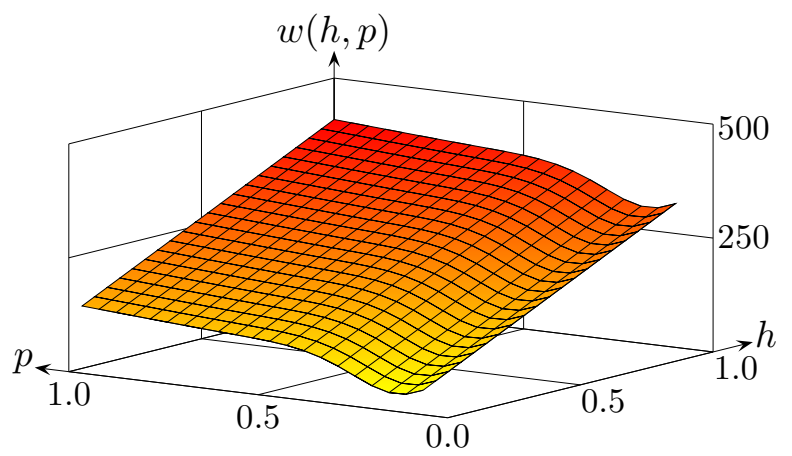

Note: For the given model specification, the production function scale parameter $\left(f_{0}\right)$ and the base offer arrival rate $(\lambda)$ are set such that the the steady state equilibrium solution satisfies $u=0.05$ and $\mathrm{E}[w(h, p)]=180.0$. The wage function is defined by $w(h, p) \equiv \int_{b}^{p} w(h, q, p) g(h, q, p) d q$.

$r=0.05, \mu=0.08, \delta_{0}=0.08, \delta_{1}=0.06, b=0.1, \alpha=0.5$, and $m=0.1$. The worker skill distribution is a truncated Weibull with support $[0,1]$, shape parameter 1.5 , scale parameter 0.45 , and origin 0.05 . The firm productivity distribution is also a truncated Weibull with support $[0,1]$, shape parameter 2.0, scale parameter 0.25 , and origin 0.1 . We will present results for different values of the worker's bargaining power. For any given choice of $\rho$, the production function scale parameter $f_{0}$ and the base offer arrival rate $\lambda$ are set so as to obtain an equilibrium steady state unemployment rate of $u=0.05$ and an average wage of $w=180$.

Figure 1 present wage function results for a worker bargaining power of $\beta=0.2$. The wage function is defined as $w(h, p) \equiv \int_{b}^{p} w(h, q, p) g(h, q, p) d q$, where $g(h, q, p)$ is the steady state match 
Figure 2: Skill and Productivity Conditional Wages $(\beta=0.5)$

(a) Supermodular $(\rho=-10)$

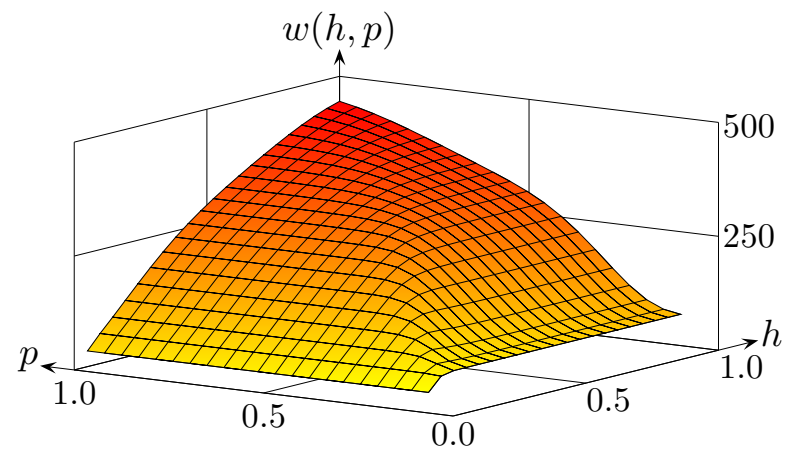

(b) Submodular $(\rho=10)$

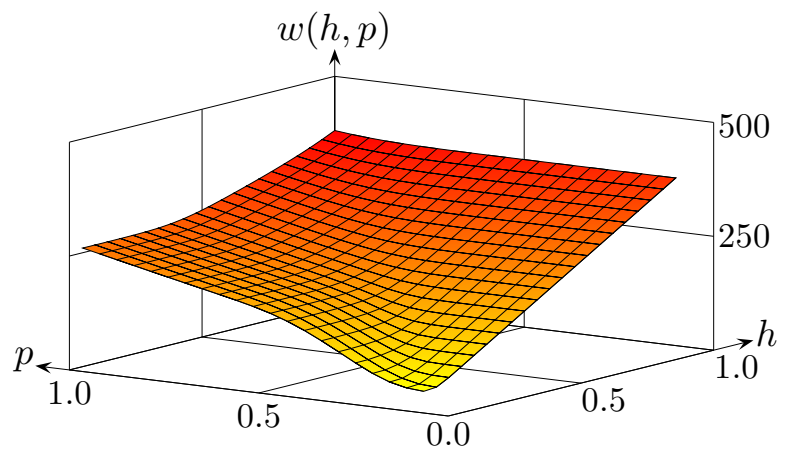

(c) Modular $(\rho=1)$

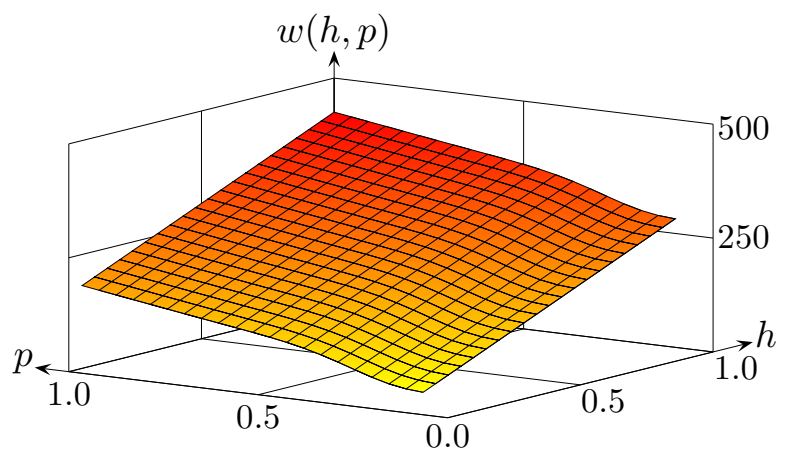

Note: For the given model specification, the production function scale parameter $\left(f_{0}\right)$ and the base offer arrival rate $(\lambda)$ are set such that the the steady state equilibrium solution satisfies $u=0.05$ and $\mathrm{E}[w(h, p)]=180.0$. The wage function is defined by $w(h, p) \equiv \int_{b}^{p} w(h, q, p) g(h, q, p) d q$.

pdf. Hence, $w(h, p)$ is the average wage realization for skill $h$ worker with a productivity $p$ firm. The figure presents the wage function for three different $\rho$ values, representing the supermodular, submodular, and modular cases. All three cases illustrate that wages may be non-monotone in firm productivity. In particular there exists regions where the average wage realization for a given firm productivity type is decreasing in firm productivity. The higher productivity firm is valuable to the worker because it increases the worker's ability to extract surplus from the next high productivity firm the worker meets. The firm can consequently extract rents from the match through a lower wage. The worker accepts the lower wage with the expectation of high future wage growth and in these cases it so happens that the wage growth tends to be realized through a move to an even 
Figure 3: The correlation between wage fixed effects and true agent heterogeneity for given $(\rho, \beta)$ combinations.
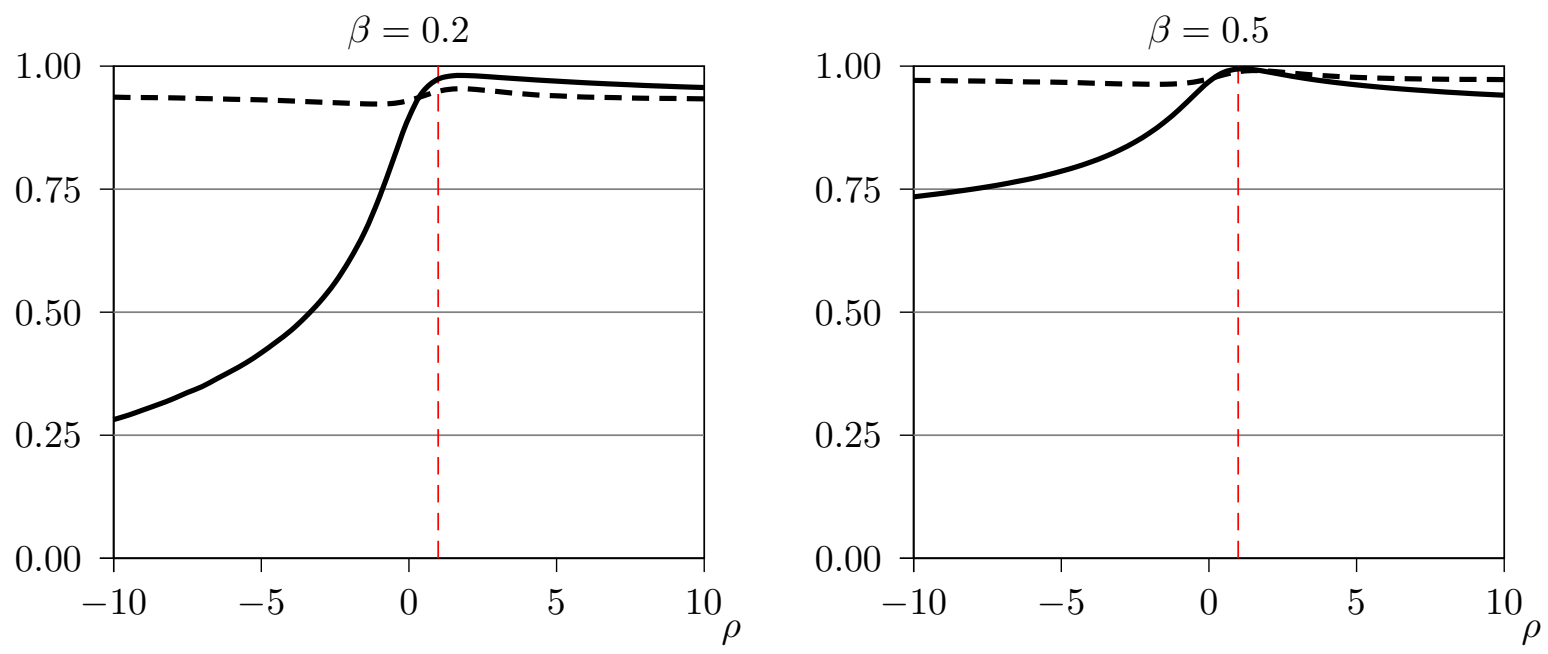

Note: The solid and dashed lines show cor $[\hat{\chi}, h]$ and $\operatorname{cor}[\hat{\varphi}, p]$, respectively. For the given model specification, the production function scale parameter $\left(f_{0}\right)$ and the base offer arrival rate $(\lambda)$ are set such that the the steady state equilibrium solution satisfies $u=0.05$ and $\mathrm{E}[w(h, p)]=180.0$. The dashed red line at $\rho=1$ divides the model specifications with positive sorting for $\rho<1$ and negative sorting for $\rho>1$.

higher productivity firm which keeps the average wage realization with the current firm type low. The supermodular case also illustrates that wages can be non-monotone in worker skill. In this case, for relatively low firm productivity types, the search intensity choices and expected gains from upward movement on the offer ladder are so much higher for high skilled workers than low skilled workers that a given firm may be so much more valuable to a high skilled worker than a low skilled worker in terms of increased wage growth expectations that the firm's rent extraction actually results in lower current wages for the high skilled worker.

Once the worker's bargaining power is increased, the non-monotonicity results begin to disappear. In the limit where $\beta=1$, the productivity of the current firm does not impact future wage negotiations with other firms, because the worker extracts full match surplus regardless. In this case, the monotonicity results on the value function in Lemma 3 carry through to the wage function. Figure 2 shows the wage functions for the case where $\beta=0.5$. Already at this point, the wage function is fundamentally reflecting the underlying characteristics of the production function $f(h, p)$ which is of course monotone in both $h$ and $p$.

In Figures 3 and 4 we relate estimates of worker and firm fixed effects from the wage equation 
(36) to the true underlying worker skill and firm productivity heterogeneity in simulations of steady state equilibria for different $(\rho, \beta)$ combinations.

Figure 3 shows $\operatorname{cor}[\hat{\chi}, h]$ and $\operatorname{cor}[\hat{\varphi}, p]$. It is seen that the wage equation firm fixed effect is strongly correlated with firm productivity regardless of the type and strength of sorting and worker's bargaining power. Not surprisingly, higher bargaining power does increase the correlation.

The correlation between the wage equation worker fixed effect and worker skill is on the other hand quite sensitive to the specification of the model. If sorting is positive and wage determination is primarily set by wage posting, then the correlation is low. In this case, the wage profiles of more skilled workers are characterized by substantial wage growth over an employment spell, and consequently, the notion of a wage equation worker fixed effect is misplaced. As documented in Figure 1 it is in this type of equilibrium also perfectly possible to observe more skilled workers receive lower wages than less skilled workers within a given firm. In such a case, the estimation will tend to rank the less skilled worker with a higher fixed effect than the more skilled worker. This mechanism is strengthened by the assumption that the wage equation has an iid over time error process, $\varepsilon_{i t}$ and the fact that even for the high skilled workers, the wage process has some permanence to it. Since the more skilled worker's realized wage growth is often associated with an actual job-to-job transition, the estimation will be allowed to explain the substantial observed wage growth of the high skilled worker by increasing the wage equation fixed effect differential between the two firms involved in the job-to-job transition, thereby laying a foundation for a negative bias in the correlation between wage equation worker and firm fixed effects. This tendency towards negative bias in the correlation between worker and firm fixed effects in the wage equation is a general point emphasized by Postel-Vinay and Robin (????). Recent work by ?? allows for a match specific effect in the wage equation which could alleviate the within firm worker effect ranking problem problem somewhat.

In the negative sorting case, low skilled workers are the ones taking temporary current wage hits with the expectation of future gains. As a result, in this type of equilibrium wages are monotonically increasing in worker skill within a given firm and the ranking of wage equation worker fixed effects will be aligned with the skill ranking. This accounts for the strong positive correlation between the 
Figure 4: The correlation between skill and productivity for given $(\rho, \beta)$ combinations.
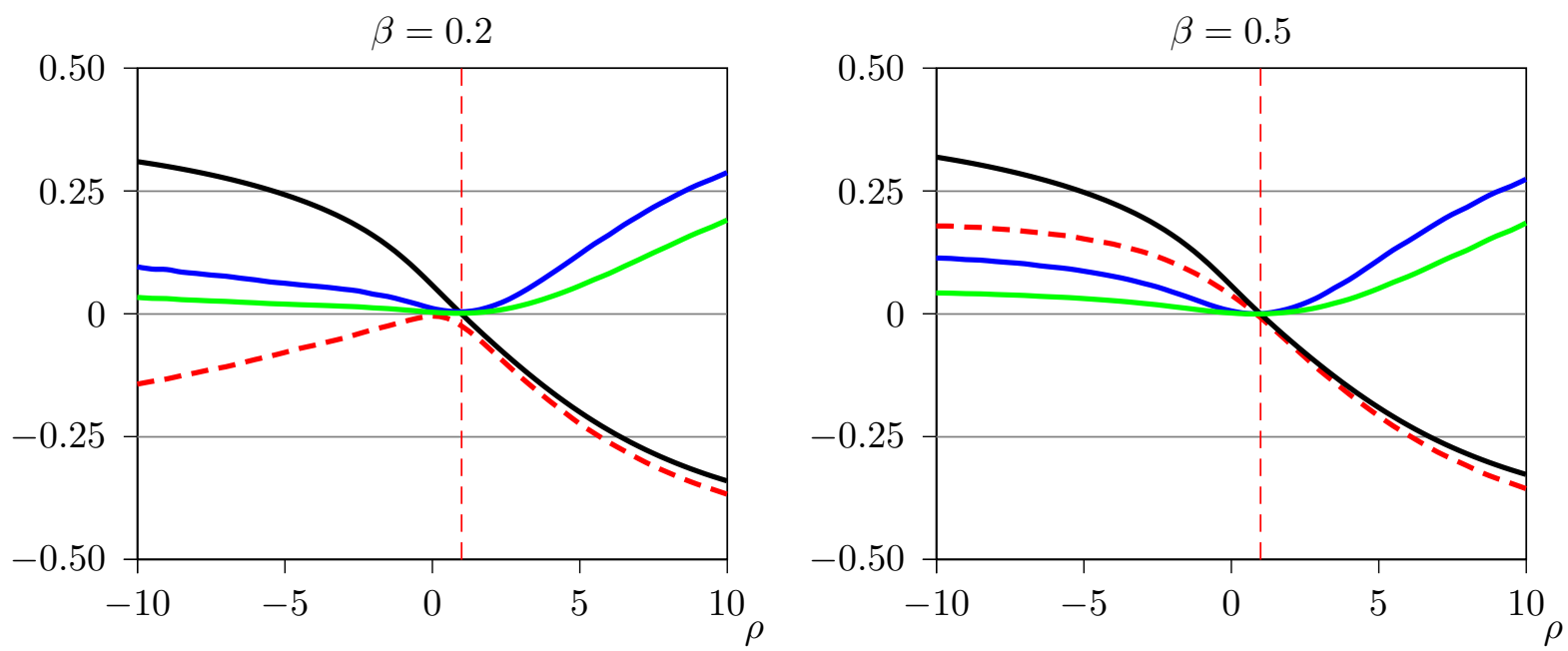

Note: The solid line is $\operatorname{cor}[h, p]$. The dashed line is $\operatorname{cor}\left[\chi_{i}, \varphi_{J(i, t)}\right]$. The blue solid line is $\operatorname{cor}\left[\chi_{i}, \bar{\chi}_{-i}\right]$. The green line shows $\nu$ as defined in equation 41. The wage equation fixed effects are estimated on simulated data from the given steady state equilibrium. For the given model specification, the production function scale parameter $\left(f_{0}\right)$ and the base offer arrival rate $(\lambda)$ are set such that the the steady state equilibrium solution satisfies $u=0.05$ and $\mathrm{E}[w(h, p)]=180.0$. The dashed red line at $\rho=1$ divides the model specifications with positive sorting for $\rho<1$ and negative sorting for $\rho>1$.

estimated wage equation worker fixed effects and worker skill for the negative sorting cases, $\rho>1$.

For higher $\beta$, where wage determination is to a greater extent set by bargaining rather than posting, $\operatorname{cor}[\chi, h]$ is higher because wages are moving towards being monotone in worker skill and firm productivity.

Figure 4 presents the correlation between the wage equation fixed effects in relation to the correlation between the skill and productivity indices in the equilibrium steady state match distribution. The correlation between $h$ and $p$ based on $G(h, p)$ reveals the basic property of the model that sorting is positive for $\rho<1$, negative for $\rho>1$, and there is no sorting when $\rho=1$. The figure also presents indicators for the distribution of worker wage fixed effects within firms relative to the overall population. One such moment suggested by Melo (2008) is the correlation between the worker fixed effect and the average worker fixed effect of the co-workers within the firm at the time of the match. Worker $i$ 's average co-worker fixed effect at time $t$ is given by,

$$
\bar{\chi}_{-i t}=\sum_{n \neq i} \mathcal{I}[J(n, t)=J(i, t)] \chi_{n} / \sum_{n \neq i} \mathcal{I}[J(n, t)=J(i, t)] .
$$


A similar moment suggested by Eeckhout and Kircher (2008) is the population variance relative to the average within firm worker fixed effect variance,

$$
\digamma=\mathrm{E}_{t}\left[\frac{\operatorname{Var}_{i}\left[\chi_{i t}\right]}{\mathrm{E}_{j}\left[\operatorname{Var}_{i}\left[\chi_{i t} \mid J(i, t)=j\right]\right]}\right]-1 .
$$

It is seen that when $\beta=0.2$ and there is negative sorting, the correlation between wage equation worker and firm fixed effects, $\mathrm{E}_{t}\left[\operatorname{cor}\left[\chi_{i}, \varphi_{J(i, t)}\right]\right]$ is very close to equilibrium steady state $\operatorname{cor}[h, p]$. This is consistent with the results in Figure 3 that the estimated wage equation worker and firm fixed effects are closely correlated with the skill and productivity indices in this case. When sorting is positive and $\beta=0.2$, we see that $\mathrm{E}_{t}\left[\operatorname{cor}\left[\chi_{i}, \varphi_{J(i, t)}\right]\right]$ and $\operatorname{cor}[h, p]$ diverge. In this case, the worker fixed effects are so poorly related to the skill ranking that the resulting negative bias drives the correlation between $\chi$ and $\varphi$ negative. As a result, $\mathrm{E}_{t}\left[\operatorname{cor}\left[\chi_{i}, \varphi_{J(i, t)}\right]\right]$ is negative both when sorting is positive and negative for this case.

In the case where $\beta=0.5$, the fixed effects correlation $\mathrm{E}_{t}\left[\operatorname{cor}\left[\chi_{i}, \varphi_{J(i, t)}\right]\right]$ does quite well in capturing the steady state match correlation between skill and productivity. There is some negative bias in the positive sorting case, but in this case, the correlation coefficients share the same signs.

The above results suggest that an observed positive value of $\mathrm{E}_{t}\left[\operatorname{cor}\left[\chi_{i}, \varphi_{J(i, t)}\right]\right]$ indicates that sorting between skill and productivity is positive. In general, the correlation coefficient between $h$ and $p$ is always greater than $\mathrm{E}_{t}\left[\operatorname{cor}\left[\chi_{i}, \varphi_{J(i, t)}\right]\right]$. It is also worth emphasizing that the oft observed small and negative correlation between $\chi$ and $\varphi$ is consistent with anything from mild negative sorting to strong positive sorting between $h$ and $p$.

The comparisons of the within firm distribution of $\chi_{i}$ relative to the population distribution, $\mathrm{E}_{t}\left[\operatorname{cor}\left[\chi_{i} t, \chi_{-i t}\right]\right]$ and $\digamma$, both suggest that a positive observed value indicate the presence of sorting between worker skill and firm productivity, but not the sign of the sorting since both measures are positive for both positive and negative sorting.

Based on the results so far, we are short of an identification strategy for $\rho$. Of course, in practice, should the observed value of $\mathrm{E}_{t}\left[\operatorname{cor}\left[\chi_{i}, \varphi_{J(i, t)}\right]\right]$ be positive, identification would be obtained. However, as a general proposition we do not have a one-to-one mapping between empirical moments and $\rho$. In the following section, we propose an identification strategy that will identify not only strength of sorting but also the sign of it. 


\subsection{Identifying the type of sorting}

As argued above, wage observations from matched employer-employee data can identify the strength of sorting. Only if observed $\mathrm{E}_{t}\left[\operatorname{cor}\left[\chi_{i}, \varphi_{J(i, t)}\right]\right]$ is positive does it also identify the type of sorting. In this section we propose an additional moment that will generally allow the identification of the type of sorting, positive or negative.

The identification strategy is focused on the correlation between inferred worker skill and unemployment durations. If sorting is positive, then high skill workers experience shorter unemployment spells than less skilled workers, and consequently the correlation between worker skill and unemployment duration should be negative. In the case where sorting is negative, less skilled workers search faster out of unemployment and the correlation should be positive. This argument uses the simple comparative statics of $s_{0}(h)$ with respect to $h$ in the model.

Unemployment duration is easily observed in data. However, as shown in detail in the previous section, worker skill is not. In particular, firm type conditional wages are generally not necessarily monotone in worker skill. There is however a subset of matches where the observed wage does reveal the worker's skill level. Worker's hired by the most productive firms directly out of unemployment receive the following wage,

$$
w(h, b, \bar{p})=(1-\beta) r V_{0}(h)+\beta f(h, \bar{p}) .
$$

Since by Lemma $3 V_{0}(h)$ is strictly increasing in $h$ it trivially follows that $w(h, b, \bar{p})$ is strictly

increasing in $h$. Hence, the workers in the group hired directly out of unemployment into top firms can be ranked according to skill directly through the wage ranking. The identification strategy then reduces to correlating the observed wage within this group with the duration of the previous unemployment spell. Thus, if unemployment duration is negatively correlated with wages within the group, sorting is positive. And if the correlation is positive, then sorting is negative.

To implement the identification strategy it then only remains to identify top productivity firms. One shortcut could be to simply rely on the wage equation firm fixed effects that seem to correlate strongly with the firm productivity. However, we do not have a proof that this strategy always works. Instead, one can use a measure of the firm's job-to-job inflow relative to the firm's total 
job-to-job flows. This is a measure that is also used in Lentz, Taber, and Vejlin (2009). The firm productivity conditional job-to-job inflow is given by,

$$
\iota(p)=\eta \nu(p) \frac{\delta_{0}+\int_{\underline{h}}^{\bar{h}} \int_{b}^{p} s\left(h^{\prime}, p^{\prime}\right) d G\left(h^{\prime}, p^{\prime}\right)}{\frac{u}{1-u} \int_{\underline{h}}^{\bar{h}}\left[\mu+s_{0}\left(h^{\prime}\right)\right] d \Upsilon\left(h^{\prime}\right)+\int_{\underline{h}}^{\bar{h}} \int_{b}^{\bar{p}}\left[\delta_{0}+s\left(h^{\prime}, p^{\prime}\right)\right] d G\left(h^{\prime}, p^{\prime}\right)} .
$$

The average job-to-job flow out of the firm is,

$$
o(p)=m_{p} \lambda \int_{\underline{h}}^{\bar{h}}\left[\delta_{0}+[1-\Gamma(p)] s\left(h^{\prime}, p\right)\right] d \Omega_{p}\left(h^{\prime}\right)=\eta \nu(p) \Lambda(\bar{h}, p)-\delta_{1} m_{p},
$$

where $m_{p}$ is the firm type conditional steady state expected labor force size.

We can then define the firm productivity conditional job-to-job inflow relative to the total jobto-job flow by, $\iota(p) /[\iota(p)+o(p)]$. This definition combined with the steady state condition on $m_{p}$ yields,

$$
\frac{\iota(p)}{\iota(p)+o(p)}=\frac{\delta_{0}+\int_{\underline{h}}^{\bar{h}} \int_{b}^{p} s\left(h^{\prime}, p^{\prime}\right) d G\left(h^{\prime}, p^{\prime}\right)}{\frac{\sigma(p)}{\delta_{1}+\sigma(p)} \frac{u}{1-u} \int_{\underline{h}}^{\bar{h}}\left[\mu+s_{0}\left(h^{\prime}\right)\right] d \Upsilon\left(h^{\prime}\right)+\left[1+\frac{\sigma(p)}{\delta_{1}+\sigma(p)}\right]\left[\delta_{0}+\int_{\underline{h}}^{\bar{h}} \int_{b}^{p} s\left(h^{\prime}, p^{\prime}\right) d G\left(h^{\prime}, p^{\prime}\right)\right]},
$$

where $\sigma(p)=\lambda \int_{\underline{h}}^{\bar{h}}\left[\delta_{0}+[1-\Gamma(p)] s\left(h^{\prime}, p\right)\right] d \Omega_{p}\left(h^{\prime}\right)$. Straightforward differentiation yields,

$$
\frac{\partial}{\partial p} \frac{\iota(p)}{\iota(p)+o(p)}>0
$$

Therefore, this empirical measure can be used to identify the firm productivity ranking of firms.

Figure 5 plots steady state equilibrium $\operatorname{cor}[\varphi, p]$ and $\operatorname{cor}[\iota(p) /(\iota(p)+o(p)), p]$ for different $(\beta, \rho)$ combinations. It is seen that both empirical measures of the firm productivity ranking perform well with the wage equation firm fixed effect doing somewhat better than the job-to-job inflow to outflow measure.

Figure 6 plots the correlation between wages and unemployment spell duration for the group of workers hired directly out of unemployment into the top $5 \%$ of firms, where the firm ranking is done either by the wage equation firm fixed effect or the job-to-job inflow relative to outflow measure. Furthermore, the figure also shows the correlation between unemployment duration and the wage equation worker fixed effect. All three measures perform well in terms of identifying the sign of sorting - the correlation is negative when sorting is positive and vice versa. The use of the wage equation firm and worker fixed effects to make inference about the underlying skill and productivity 
Figure 5: Identification of firm productivity for given $(\rho, \beta)$ combinations.
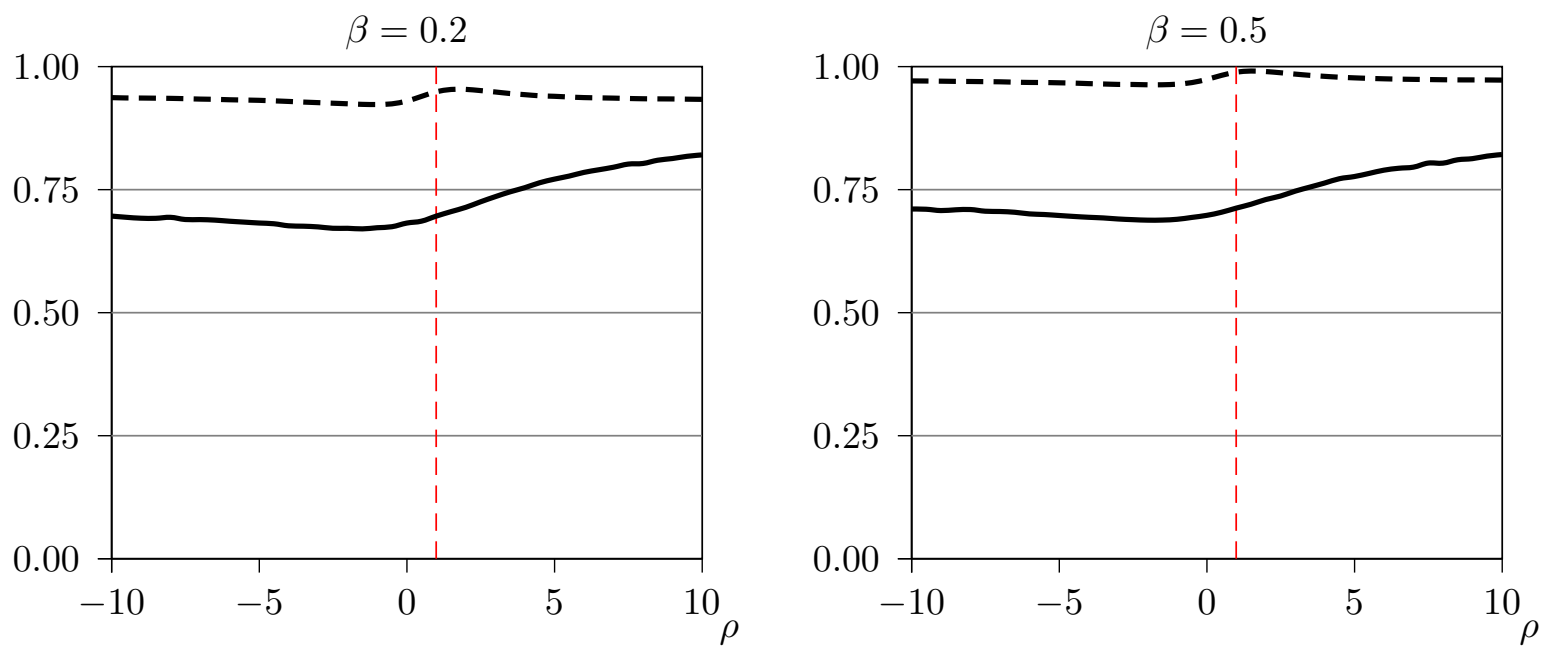

Note: The solid and dashed lines show $\operatorname{cor}[\iota(p) /(\iota(p)+o(p)), p]$ and $\operatorname{cor}[\hat{\varphi}, p]$, respectively. For the given model specification, the production function scale parameter $\left(f_{0}\right)$ and the base offer arrival rate $(\lambda)$ are set such that the the steady state equilibrium solution satisfies $u=0.05$ and $\mathrm{E}[w(h, p)]=180.0$. The dashed red line at $\rho=1$ divides the model specifications with positive sorting for $\rho<1$ and negative sorting for $\rho>1$.

indices works quite well for the cases that we have presented. But as emphasized before, we do not have proof that this will be the case for any model specification. The job-to-job inflow to outflow measure does identify the firm productivity ranking but in practice it is somewhat noisy.

The moments in Figure 6 in combination with the correlation between worker and firm fixed effects as well as the comparison of the within firm wage equation worker fixed effect relative to the overall population provide a successful foundation for identification not only of the presence of sorting between skill and productivity but also the sign of the sorting.

\section{$5 \quad$ Model Estimation}

To be completed.

\section{Summary}

To be completed. 
Figure 6: Identification of type of sorting for given $(\rho, \beta)$ combinations.
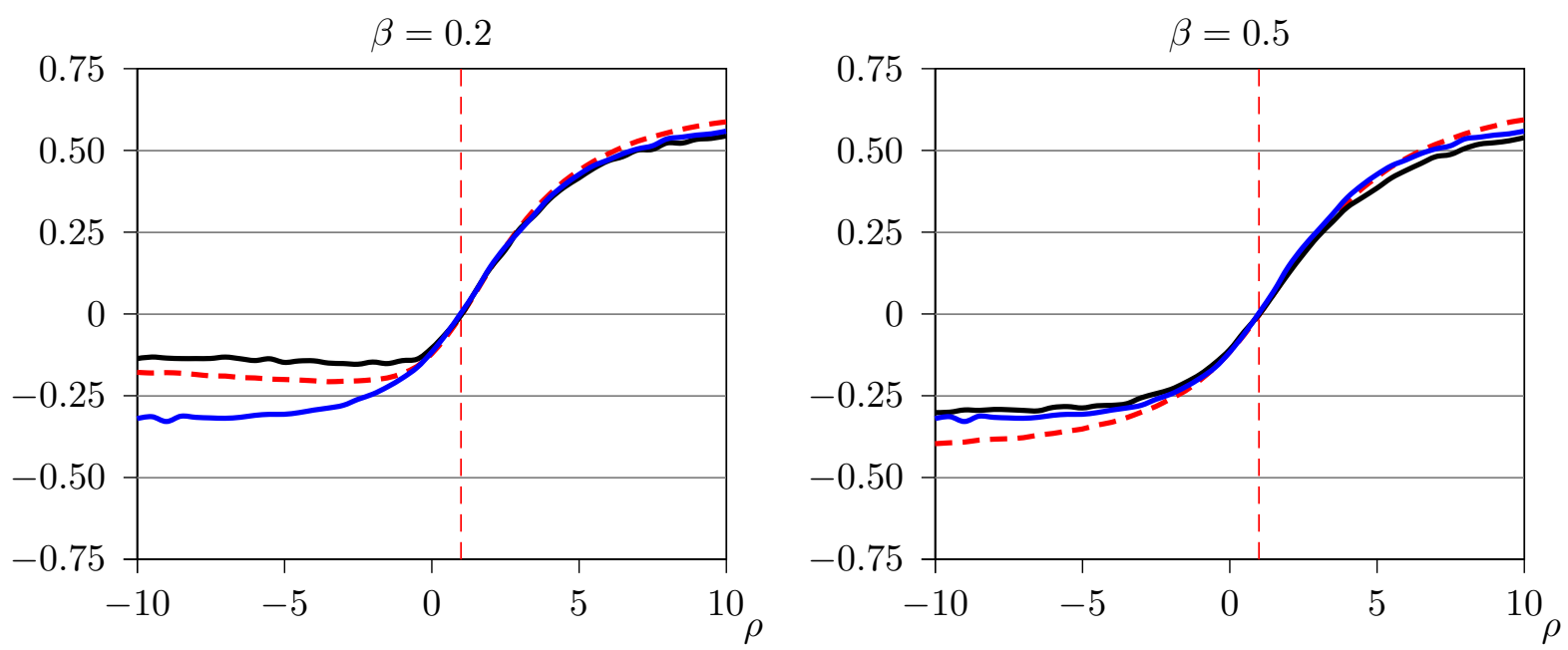

Note: The solid black line is the corrrelation between wages and unemployment duration for workers hired directly into the top $5 \%$ of firms ranked by the job-to-job inflow to outflow measure. The solid blue line present the same correlation but using the wage equation firm fixed effect to identify the top $5 \%$ of the firms. The dashed red line shows the correlation between unemployment duration and the wage equation worker fixed effect. For the given model specification, the production function scale parameter $\left(f_{0}\right)$ and the base offer arrival rate $(\lambda)$ are set such that the the steady state equilibrium solution satisfies $u=0.05$ and $\mathrm{E}[w(h, p)]=180.0$. The dashed red line at $\rho=1$ divides the model specifications with positive sorting for $\rho<1$ and negative sorting for $\rho>1$.

\section{A Detailed derivations}

Consider an employed worker of type $h$ who is employed with a type $p$ firm at employment contract $(w, s)$. Denote by $q=q(h, w, p)$, the threshold type such that a meeting of an outside firm with type less than $q$ has no impact on the worker's wage. Furthermore, adopt the short hand $V(h, q, p)$ as the value of employment to a type $h$ worker who is employed with a type $p$ firm subject to an employment contract set through bargaining where the worker had the threat point to accept outside employment with a type $q$ firm. The value function, $\tilde{V}(h, w, p, s)$, for the employed worker 
is,

$$
\begin{aligned}
r \tilde{V}(h, p, w, s)= & w-c(s)+\left[\delta_{1}+\Gamma(R(h)) \delta_{0} \lambda(\theta)\right]\left[V_{0}(h)-V(h, q, p)\right]+ \\
& s \lambda(\theta) \int_{p}^{\bar{p}}\left[V\left(h, p, p^{\prime}\right)-V(h, q, p)\right] d \Gamma\left(p^{\prime}\right)+ \\
& s \lambda(\theta) \int_{q}^{p}\left[V\left(h, p^{\prime}, p\right)-V(h, q, p)\right] d \Gamma\left(p^{\prime}\right)+ \\
& \delta_{0} \lambda(\theta) \int_{R(h)}^{\bar{p}}\left[V\left(h, R(h), p^{\prime}\right)-V(h, q, p)\right] d \Gamma\left(p^{\prime}\right) \\
= & w-c(s)+\left[\delta_{1}+\Gamma(R(h)) \delta_{0} \lambda(\theta)\right] V_{0}(h)-\left[\delta_{0} \lambda(\theta)+\delta_{1}+s \lambda(\theta)(1-\Gamma(q))\right] V(h, q, p)+ \\
& s \lambda(\theta) \int_{p}^{\bar{p}}\left[\beta V\left(h, p^{\prime}, p^{\prime}\right)+(1-\beta) V(h, p, p)\right] d \Gamma\left(p^{\prime}\right)+ \\
& s \lambda(\theta) \int_{q}^{p}\left[\beta V(h, p, p)+(1-\beta) V\left(h, p^{\prime}, p^{\prime}\right)\right] d \Gamma\left(p^{\prime}\right)+ \\
& \delta_{0} \lambda(\theta) \int_{R(h)}^{\bar{p}}\left[\beta V\left(h, p^{\prime}, p^{\prime}\right)+(1-\beta) V_{0}(h)\right] d \Gamma\left(p^{\prime}\right)
\end{aligned}
$$

Integration by parts yields,

$$
\begin{aligned}
\left(r+\delta_{0} \lambda(\theta)+\delta_{1}\right) \tilde{V}(h, p, w, s)= & w-c(s)+\left[\delta_{1}+\Gamma(R(h)) \delta_{0} \lambda(\theta)\right] V_{0}(h)-s \lambda(\theta)(1-\Gamma(q)) V(h, q, p)+ \\
& s \lambda(\theta)(1-\beta)(1-\Gamma(p)) V(h, p, p)+s \lambda(\theta) \beta(1-\Gamma(p)) V(h, p, p)+ \\
& s \lambda(\theta) \beta \int_{p}^{\bar{p}}\left(1-\Gamma\left(p^{\prime}\right)\right) V_{p}^{\prime}\left(h, p^{\prime}, p^{\prime}\right) d p^{\prime}+ \\
& s \lambda(\theta) \beta(\Gamma(p)-\Gamma(q)) V(h, p, p)-s \lambda(\theta)(1-\beta)(1-\Gamma(p)) V(h, p, p)+ \\
& s \lambda(\theta)(1-\beta)(1-\Gamma(q)) V(h, q, q)+s \lambda(\theta)(1-\beta) \int_{q}^{p}\left(1-\Gamma\left(p^{\prime}\right)\right) V^{\prime}\left(h, p^{\prime}, p^{\prime}\right) d p^{\prime}+ \\
& \delta_{0} \lambda(\theta)(1-\beta)[1-\Gamma(R(h))] V_{0}(h)+\delta_{0} \lambda(\theta) \beta[1-\Gamma(R(h))] V_{0}(h)+ \\
& \delta_{0} \lambda(\theta) \beta \int_{R(h)}^{\bar{p}}\left[1-\Gamma\left(p^{\prime}\right)\right] V^{\prime}\left(h, p^{\prime}, p^{\prime}\right) d p^{\prime}
\end{aligned}
$$

By $V(h, q, p)=\beta V(h, p, p)+(1-\beta) V(h, q, q)$, one obtains.

$$
\begin{aligned}
\left(r+\delta_{0} \lambda(\theta)+\delta_{1}\right) \tilde{V}(h, p, w, s)= & f(h, p)-c(s)+\left(\delta_{0} \lambda(\theta)+\delta_{1}\right) V_{0}(h)+ \\
& s \lambda(\theta) \beta \int_{p}^{\bar{p}} V^{\prime}\left(h, p^{\prime}, p^{\prime}\right)\left[1-\Gamma\left(p^{\prime}\right)\right] d p^{\prime}+ \\
& s \lambda(\theta)(1-\beta) \int_{q}^{p} V^{\prime}\left(h, p^{\prime}, p^{\prime}\right)\left[1-\Gamma\left(p^{\prime}\right)\right] d p^{\prime}+ \\
& \delta_{0} \lambda(\theta) \beta \int_{R(h)}^{\bar{p}} V^{\prime}\left(h, p^{\prime}, p^{\prime}\right)\left[1-\Gamma\left(p^{\prime}\right)\right] d p^{\prime} .
\end{aligned}
$$


By the envelope theorem it follows that,

$$
\begin{aligned}
\left(r+\delta_{0} \lambda(\theta)+\delta_{1}\right) V_{p}^{\prime}(h, p, p) & =f_{p}^{\prime}(h, p)-s(h, p) \lambda(\theta) \beta(1-\Gamma(p)) V_{p}^{\prime}(h, p, p) \\
& \Uparrow \\
V_{p}^{\prime}(h, p, p) & =\frac{f_{p}^{\prime}(h, p)}{r+\delta_{0} \lambda(\theta)+\delta_{1}+\beta s(h, p) \lambda(\theta)(1-\Gamma(p))} .
\end{aligned}
$$

Hence, equation (53) can be written as,

$$
\begin{aligned}
\left(r+\delta_{0} \lambda(\theta)+\delta_{1}\right) \tilde{V}(h, p, w, s)= & w-c(s)+\left(\delta_{0} \lambda(\theta)+\delta_{1}\right) V_{0}(h)+ \\
& s \lambda(\theta) \beta \int_{p}^{\bar{p}} \frac{f_{p}^{\prime}\left(h, p^{\prime}\right)\left[1-\Gamma\left(p^{\prime}\right)\right] d p^{\prime}}{r+\delta_{0} \lambda(\theta)+\delta_{1}+\beta s\left(h, p^{\prime}\right) \lambda(\theta)\left[1-\Gamma\left(p^{\prime}\right)\right]}+ \\
& s \lambda(\theta)(1-\beta) \int_{q}^{p} \frac{f_{p}^{\prime}\left(h, p^{\prime}\right)\left[1-\Gamma\left(p^{\prime}\right)\right] d p^{\prime}}{r+\delta_{0} \lambda(\theta)+\delta_{1}+\beta s\left(h, p^{\prime}\right) \lambda(\theta)\left[1-\Gamma\left(p^{\prime}\right)\right]}+ \\
& \delta_{0} \lambda(\theta) \beta \int_{R(h)}^{\bar{p}} \frac{f_{p}^{\prime}\left(h, p^{\prime}\right)\left[1-\Gamma\left(p^{\prime}\right)\right] d p^{\prime}}{r+\delta_{0} \lambda(\theta)+\delta_{1}+\beta s\left(h, p^{\prime}\right) \lambda(\theta)\left[1-\Gamma\left(p^{\prime}\right)\right]} .
\end{aligned}
$$

\section{A.1 Steady state $G(h, q, p)$}

The steady state condition on $G(h, q, p)$ is given by,

$$
\begin{array}{r}
(1-u) \delta G(h, q, p)+(1-u) \lambda(\theta) \int_{\underline{h}}^{h} \int_{R\left(h^{\prime}\right)}^{q}\left\{(1-\Gamma(p)) \int_{q^{\prime}}^{q} s\left(h^{\prime}, p^{\prime}\right) d G\left(h^{\prime}, q^{\prime}, p^{\prime}\right)\right. \\
\left.+(1-\Gamma(q)) \int_{q}^{p} s\left(h^{\prime}, p^{\prime}\right) d G\left(h^{\prime}, q^{\prime}, p^{\prime}\right)\right\}= \\
\int_{\underline{h}}^{h} I\left(R\left(h^{\prime}\right) \leq q\right)\left[\Gamma(p)-\Gamma\left(R\left(h^{\prime}\right)\right)\right] \lambda(\theta)\left[u\left[\delta_{0}+\kappa s_{0}\left(h^{\prime}\right)\right] v\left(h^{\prime}\right)+\right. \\
\left.(1-u) \delta_{0} \int_{R\left(h^{\prime}\right)}^{\bar{p}} \int_{q^{\prime}}^{\bar{p}} g\left(h^{\prime}, q^{\prime}, p^{\prime}\right) d p^{\prime} d q^{\prime}\right] d h^{\prime} .
\end{array}
$$

Evaluate at $(h, \bar{p}, \bar{p})$ and differentiate with respect to $h$ to obtain,

$$
\begin{aligned}
& \left(\delta_{0} \lambda(\theta)+\delta_{1}\right)(1-u) \int_{R(h)}^{\bar{p}} \int_{q^{\prime}}^{\bar{p}} g\left(h, q^{\prime}, p^{\prime}\right) d p^{\prime} d q^{\prime}=[1-\Gamma(R(h))] \lambda(\theta)\left\{u\left[\mu+\kappa s_{0}(h)\right] v\left(h^{\prime}\right)+\right. \\
& \left.(1-u) \delta_{0} \int_{R(h)}^{\bar{p}} \int_{q^{\prime}}^{\bar{p}} g\left(h, q^{\prime}, p^{\prime}\right) d p^{\prime} d q^{\prime}\right\} \\
& \Uparrow \\
& \left(\delta_{0} \lambda(\theta) \Gamma(R(h))+\delta_{1}\right)(1-u) \int_{R(h)}^{\bar{p}} \int_{q^{\prime}}^{\bar{p}} g\left(h, q^{\prime}, p^{\prime}\right) d p^{\prime} d q^{\prime}=u[1-\Gamma(R(h))] \lambda(\theta)\left[\mu+\kappa s_{0}(h)\right] v(h) \\
& \Uparrow \\
& \delta_{0}(1-u) \int_{R(h)}^{\bar{p}} \int_{q^{\prime}}^{\bar{p}} g\left(h, q^{\prime}, p^{\prime}\right) d p^{\prime} d q^{\prime}=\frac{\delta_{0} \lambda(\theta)[1-\Gamma(R(h))]}{\delta_{0} \lambda(\theta) \Gamma(R(h))+\delta_{1}} u\left[\mu+\kappa s_{0}(h)\right] v(h(f) 49)
\end{aligned}
$$


Insert this into equation (48),

$$
\begin{array}{r}
\frac{\delta_{0} \lambda(\theta)+\delta_{1}}{\lambda(\theta)} G(h, q, p)+\int_{\underline{h}}^{h} \int_{R\left(h^{\prime}\right)}^{q}\left[[1-\Gamma(p)] \int_{q^{\prime}}^{q} s\left(h^{\prime}, p^{\prime}\right) d G\left(h^{\prime}, q^{\prime}, p^{\prime}\right)\right. \\
\left.+[1-\Gamma(q)] \int_{q}^{p} s\left(h^{\prime}, p^{\prime}\right) d G\left(h^{\prime}, q^{\prime}, p^{\prime}\right)\right]= \\
\frac{u}{1-u} \int_{\underline{h}}^{h} I\left(R\left(h^{\prime}\right) \leq p\right)\left[\Gamma(p)-\Gamma\left(R\left(h^{\prime}\right)\right)\right]\left[\mu+\kappa s_{0}\left(h^{\prime}\right)\right] v\left(h^{\prime}\right) \frac{\delta_{1}+\delta_{0} \lambda(\theta)}{\delta_{0} \lambda(\theta) \Gamma(R(h))+\delta_{1}} d h^{\prime} .
\end{array}
$$

Evaluate $(50)$ at $(\bar{h}, \bar{p}, \bar{p})$ to obtain,

$$
\begin{aligned}
\frac{\delta_{0} \lambda(\theta)+\delta_{1}}{\lambda(\theta)} & =\frac{u}{1-u} \int_{\underline{h}}^{\bar{h}}\left[1-\Gamma\left(R\left(h^{\prime}\right)\right)\right] \frac{\delta_{1}+\delta_{0} \lambda(\theta)}{\delta_{0} \lambda(\theta) \Gamma(R(h))+\delta_{1}}\left[\mu+\kappa s_{0}\left(h^{\prime}\right)\right] v\left(h^{\prime}\right) d h^{\prime} \\
& \mathbb{1} \\
\frac{u}{1-u} & =\left[\int_{\underline{h}}^{\bar{h}} \frac{\left[1-\Gamma\left(R\left(h^{\prime}\right)\right)\right]\left[\mu+\kappa s_{0}\left(h^{\prime}\right)\right]}{\delta_{0} \Gamma\left(R\left(h^{\prime}\right)\right)+\delta_{1} / \lambda(\theta)} v\left(h^{\prime}\right) d h^{\prime}\right]^{-1} \\
& \mathbb{\mathbb { }} \\
u & =\left[\int_{\underline{h}}^{\bar{h}}\left(1+\frac{\left[1-\Gamma\left(R\left(h^{\prime}\right)\right)\right]\left[\mu+\kappa s_{0}\left(h^{\prime}\right)\right]}{\delta_{0} \Gamma\left(R\left(h^{\prime}\right)\right)+\delta_{1} / \lambda(\theta)}\right) d \Upsilon\left(h^{\prime}\right)\right]^{-1} .
\end{aligned}
$$

One then obtains,

$$
\begin{gathered}
\int_{\underline{h}}^{h} \int_{R\left(h^{\prime}\right)}^{q}\left[\int_{q^{\prime}}^{q}\left[\delta / \lambda(\theta)+[1-\Gamma(p)] s\left(h^{\prime}, p^{\prime}\right)\right] g\left(h^{\prime}, q^{\prime}, p^{\prime}\right) d p^{\prime}\right. \\
\left.+\int_{q}^{p}\left[\delta / \lambda(\theta)+[1-\Gamma(q)] s\left(h^{\prime}, p^{\prime}\right)\right] g\left(h^{\prime}, q^{\prime}, p^{\prime}\right) d p^{\prime}\right] d q^{\prime} d h^{\prime}= \\
\frac{\delta}{\lambda(\theta)} \frac{\int_{\underline{h}}^{h} I\left(R\left(h^{\prime}\right) \leq q\right)\left[\Gamma(p)-\Gamma\left(R\left(h^{\prime}\right)\right)\right] \frac{\mu+\kappa s_{0}\left(h^{\prime}\right)}{\delta_{0} \Gamma\left(R\left(h^{\prime}\right)\right)+\delta_{1} / \lambda(\theta)} d \Psi\left(h^{\prime}\right)}{\int_{\underline{h}}^{\bar{h}} \frac{\left[1-\Gamma\left(R\left(h^{\prime}\right)\right)\right]\left[\mu+\kappa s_{0}\left(h^{\prime}\right)\right]}{\delta_{0} \Gamma\left(R\left(h^{\prime}\right)\right)+\delta_{1} / \lambda(\theta)} d \Psi\left(h^{\prime}\right)} .
\end{gathered}
$$

\section{A.2 Steady state equilibrium solution for $\Upsilon(h)$}

Consider the equilibrium condition,

$$
\Psi(h)=u \Upsilon(h)+(1-u) G(h, \bar{p}) .
$$

Differentiate with respect to $h$ to obtain,

$$
\begin{aligned}
\psi(h) & =u v(h)+(1-u) \int_{b}^{\bar{p}} g\left(h, p^{\prime}\right) d p^{\prime} \\
& =\left[1+\frac{[1-\Gamma(R(h))]\left[\mu+\kappa s_{0}(h)\right]}{\delta_{0} \Gamma(R(h))+\delta_{1} / \lambda(\theta)}\right] u v(h),
\end{aligned}
$$


where the last equality follows from equation (49). By the steady state unemployment rate expression in equation (??), it follows that,

$$
\psi(h)=\frac{\left[1+\frac{\left.[1-\Gamma(R(h))]\left[\mu+\kappa s_{0}(h)\right]\right]}{\delta_{0} \Gamma(R(h))+\delta_{1} / \lambda(\theta)}\right] v(h)}{\int_{\underline{h}}^{\bar{h}}\left(1+\frac{\left[1-\Gamma\left(R\left(h^{\prime}\right)\right)\right]\left[\mu+\kappa s_{0}\left(h^{\prime}\right)\right]}{\delta_{0} \Gamma\left(R\left(h^{\prime}\right)\right)+\delta_{1} / \lambda(\theta)}\right) v\left(h^{\prime}\right) d h^{\prime}},
$$

which is an integral equation for $\Upsilon(h)$ as a function of $\Psi(h)$. Define,

$$
\Delta(h)=\frac{[1-\Gamma(R(h))]\left[\mu+\kappa s_{0}(h)\right]}{\delta_{0} \Gamma(R(h))+\delta_{1} / \lambda(\theta)} .
$$

Then restate equation (52),

$$
v(h)=\left[1+\int_{\underline{h}}^{\bar{h}} \Delta\left(h^{\prime}\right) v\left(h^{\prime}\right) d h^{\prime}\right] \frac{\psi(h)}{1+\Delta(h)} .
$$

Use equation (52) to solve for $1+\int_{\underline{h}}^{\bar{h}} \Delta\left(h^{\prime}\right) v\left(h^{\prime}\right) d h^{\prime}$. First, some minor manipulation,

$$
\begin{aligned}
\psi(h)+\psi(h) \int_{\underline{h}}^{\bar{h}} \Delta\left(h^{\prime}\right) v\left(h^{\prime}\right) d h^{\prime} & =[1+\Delta(h)] v(h) \\
& \mathbb{\Downarrow} \\
v(h)-\frac{\psi(h)}{1+\Delta(h)} \int_{\underline{h}}^{\bar{h}} \Delta\left(h^{\prime}\right) v\left(h^{\prime}\right) d h^{\prime} & =\frac{\psi(h)}{1+\Delta(h)} \\
& \mathbb{1} \\
\Delta(h) v(h)-\frac{\psi(h) \Delta(h)}{1+\Delta(h)} \int_{\underline{h}}^{\bar{h}} \Delta\left(h^{\prime}\right) v\left(h^{\prime}\right) d h^{\prime} & =\frac{\psi(h) \Delta(h)}{1+\Delta(h)} .
\end{aligned}
$$

Now, integrate from $\underline{h}$ to $\bar{h}$ to obtain,

$$
\begin{aligned}
\int_{\underline{h}}^{\bar{h}} \Delta\left(h^{\prime}\right) v\left(h^{\prime}\right) d h^{\prime}\left[1-\int_{\underline{h}}^{\bar{h}} \frac{\psi\left(h^{\prime}\right) \Delta\left(h^{\prime}\right)}{1+\Delta\left(h^{\prime}\right)} d h^{\prime}\right] & =\int_{\underline{h}}^{\bar{h}} \frac{\psi\left(h^{\prime}\right) \Delta\left(h^{\prime}\right)}{1+\Delta\left(h^{\prime}\right)} d h^{\prime} \\
1+\int_{\underline{h}}^{\bar{h}} \Delta\left(h^{\prime}\right) v\left(h^{\prime}\right) d h^{\prime} & =1+\frac{\int_{\underline{h}}^{\bar{h}} \frac{\psi\left(h^{\prime}\right) \Delta\left(h^{\prime}\right)}{1+\Delta\left(h^{\prime}\right)} d h^{\prime}}{1-\int_{\underline{h}}^{\bar{h}} \frac{\psi\left(h^{\prime}\right) \Delta\left(h^{\prime}\right)}{1+\Delta\left(h^{\prime}\right)} d h^{\prime}} \\
& =\frac{1}{1-\int_{\underline{h}}^{\bar{h}} \frac{\Delta\left(h^{\prime}\right)}{1+\Delta\left(h^{\prime}\right)} \psi\left(h^{\prime}\right) d h^{\prime}} \\
& =\frac{1}{\int_{\underline{h}}^{\bar{h}}\left[1-\frac{\Delta\left(h^{\prime}\right)}{1+\Delta\left(h^{\prime}\right)}\right]\left(h^{\prime}\right) d h^{\prime}} \\
& =\frac{1}{\int_{\underline{h}}^{\bar{h}} \frac{1}{1+\Delta\left(h^{\prime}\right)} \psi\left(h^{\prime}\right) d h^{\prime}} .
\end{aligned}
$$


Hence, one obtains the solution,

$$
v(h)=\frac{[1+\Delta(h)]^{-1} \psi(h)}{\int_{\underline{h}}^{\bar{h}}\left[1+\Delta\left(h^{\prime}\right)\right]^{-1} \psi\left(h^{\prime}\right) d h^{\prime}},
$$

which can also be written as,

$$
\Upsilon(h)=\frac{\int_{\underline{h}}^{h} \frac{\delta_{0} \Gamma\left(R\left(h^{\prime}\right)\right)+\delta_{1} / \lambda(\theta)}{\delta_{0} \Gamma\left(R\left(h^{\prime}\right)\right)+\delta_{1} / \lambda(\theta)+\left[1-\Gamma\left(R\left(h^{\prime}\right)\right)\right]\left[\mu+\kappa s_{0}\left(h^{\prime}\right)\right]} d \Psi\left(h^{\prime}\right)}{\int_{\underline{h}}^{\bar{h}} \frac{\delta_{0} \Gamma\left(R\left(h^{\prime}\right)\right)+\delta_{1} / \lambda(\theta)}{\delta_{0} \Gamma\left(R\left(h^{\prime}\right)\right)+\delta_{1} / \lambda(\theta)+\left[1-\Gamma\left(R\left(h^{\prime}\right)\right)\right]\left[\mu+\kappa s_{0}\left(h^{\prime}\right)\right]} d \Psi\left(h^{\prime}\right)} .
$$

\section{B Firm labor force composition is independent of firm size}

Consider a labor force that consists of $k$ types. For the purpose of this argument, a type $i$ worker is characterized by a hire rate $h_{i}$ and a separation rate $d_{i}$. Firm entry and exit takes place through the zero labor force size pool. Each worker $i$ size process is independent. Hence, the distribution of the number of type $i$ workers employed by the firm will be Poisson distributed,

$$
m_{n}^{i}=\frac{\left(\frac{h_{i}}{d_{i}}\right)^{n} \exp \left(-\frac{h_{i}}{d_{i}}\right)}{n !} .
$$

Denote by $\vec{n}=\left(n_{1}, n_{2}, \ldots, n_{k}\right)$ the composition of the firm's labor force. The mass of size $n$ firms is formed based on the sum of the individual worker type distributions,

$$
\begin{aligned}
m_{n} & =\sum_{\left\{\vec{n} \geq 0 \mid \sum n_{i}=n\right\}} \prod_{i=1}^{k} m_{n_{i}}^{i} \\
& =\frac{\left[\sum_{i=1}^{k} \frac{h_{i}}{d_{i}}\right]^{n} \exp \left(-\sum_{i=1}^{k} \frac{h_{i}}{d_{i}}\right)}{n !}
\end{aligned}
$$

which is just a Poisson in the sum of the individual hiring and separation rate fraction. Consider the expectation of the share of type $i$ workers in the firm's labor force conditional on the firm 
having $n$ workers,

$$
\begin{aligned}
E\left[\frac{n_{i}}{n} \mid n\right]= & \frac{\sum_{\left\{\vec{n} \geq 0 \mid \sum n_{j}=n\right\}} \frac{n_{i}}{n} \prod_{j=1}^{k} m_{n_{j}}^{j}}{m_{n}} \\
= & \frac{\sum_{\left\{\vec{n} \geq 0 \mid \sum n_{j}=n\right\}} n ! \frac{n_{i}}{n} \frac{\prod_{j=1}^{k}\left(\frac{\eta_{j}}{\delta_{j}}\right)^{n_{j}}}{\prod_{j=1}^{k} n_{j} !}}{\sum_{\left\{\vec{n} \geq 0 \mid \sum n_{j}=n\right\}} n ! \frac{\prod_{j=1}^{k}\left(\frac{\eta_{j}}{\delta_{j}}\right)^{n_{j}}}{\prod_{j=1}^{k} n_{j} !}} \\
= & \frac{\left(\frac{\eta_{i}}{\delta_{i}}\right)\left[\sum_{i=1}^{k} \frac{h_{i}}{d_{i}}\right]^{n-1}}{\left[\sum_{i=1}^{k} \frac{h_{i}}{d_{i}}\right]^{n}} \\
= & \frac{\frac{h_{i}}{d_{i}}}{\sum_{i=1}^{k} \frac{h_{i}}{d_{i}}}
\end{aligned}
$$

where the second to last step applies the multinomial theorem. Hence, the share of type $i$ workers in the firm's labor force is independent of the size of the firm's labor force. Consequently, the firm's overall worker separation rate is not size dependent.

\section{Employment contract bargaining}

At the beginning of an employment relationship, the firm and the worker bargain over a constant wage and worker's search intensity that will remain in effect until the relationship terminates or both parties consent to renegotiation. The bargaining game is an application of the alternating

offers game of Rubinstein (1982) and most resembles the exogenous break down version as presented in Binmore, Rubinstein, and Wolinsky (1986). The following two subsections present the subgame perfect equilibrium for the case of an unemployed worker worker and a worker who is renegotiating subsequent to an outside offer, respectively. The arguments are closely related to the bargaining games described in Cahuc, Postel-Vinay, and Robin (2006), although the bargaining is simplified to take place in artificial time with zero disagreement values and the possibility of meeting another employer during bargaining is eliminated.

The outcomes of the alternating offers games are identical to that of axiomatic Nash bargaining where the threat point of the firm is always zero for the firm, and the worker's threat point is either unemployment or full surplus extraction from the least productive of the two firms competing over the worker. This is the argument presented in Dey and Flinn (2005). Specifically, the bargaining 
outcome of an unemployed worker maximizes the Nash product,

$$
\left\{w_{0}(h, p), s(h, p)\right\}=\arg \max _{w, s}\left(\tilde{V}(h, p, w, s)-V_{0}(h)\right)^{\beta} \tilde{J}(h, w, p, s)^{(1-\beta)}
$$

which yields the worker valuation,

$$
V(h, R(h), p)=\beta V(h, p, p)+(1-\beta) V_{0}(h) .
$$

The inclusion of the reservation productivity argument implicitly states that the worker will only accept to bargain with employer types greater than $R(h)$.

The outcome of a worker bargaining with two employer types, $q$ and $p$ such that $p>q$ is that the worker will negotiate an employment contract with the type $p$ firm with a threat point of full surplus extraction and efficient search intensity with the lower type firm, $V(h, q, q)$. Hence, the employment contract that results from this bargaining setting is,

$$
\{w(h, q, p), s(h, p)\}=\arg \max _{w, s}(\tilde{V}(h, p, w, s)-V(h, q, q))^{\beta} \tilde{J}(h, w, p, s)^{(1-\beta)} .
$$

The bargaining outcome is,

$$
V(h, q, p)=\beta V(h, p, p)+(1-\beta) V(h, q, q) .
$$

In both cases (53) and (55), the agreed upon search intensity $s(h, p)$ is the one that maximizes total match surplus. This is the jointly efficient search intensity level and does not depend on the specific surplus split dictated by bargaining power and threat points.

\section{C.1 Unemployed worker}

Consider an alternating offers game where the worker makes an offer $\left(w_{e}, s_{e}\right)$ to the firm. If the firm accepts, employment starts and the worker receives payoff $\tilde{V}\left(h, p, w_{e}, s_{e}\right)$ and the firm receives $\tilde{J}\left(h, p, w_{e}, s_{e}\right)=\tilde{V}\left(h, p, f(h, p), s_{e}\right)-\tilde{V}\left(h, p, w_{e}, s_{e}\right)$. If the firm rejects the offer, the bargaining breaks down with exogenous probability $\Delta$. If so, the firm receives a zero payoff and the worker goes back to unemployment and receives $V_{0}(h)$. If bargaining does not break down, the bargaining moves to the next round where the firm makes an offer $\left(w_{f}, s_{f}\right)$ with probability $1-\beta$ and the worker gets to make the offer $\left(w_{e}, s_{e}\right)$ with probability $\beta$. If the firm

makes the offer and the worker accepts, the worker receives $\tilde{V}\left(h, p, w_{f}, s_{f}\right)$ and the firm receives 
$\tilde{J}\left(h, p, w_{f}, s_{f}\right)=\tilde{V}\left(h, p, f(h, p), s_{f}\right)-\tilde{V}\left(h, p, w_{f}, s_{f}\right)$. If the worker rejects, the game moves on to the next round if no break down occurs. And again, the worker will make the offer with probability $\beta$ and the firm with probability $1-\beta$. The game continues like this ad infinitum or until agreement is reached. Disagreement payoffs are zero and the discount rate between rounds is zero.

Both the worker and the firm will offer the same search intensity, $s_{e}=s_{f}=s(h, p)$, where $s(h, p)=\arg \max _{s} \tilde{V}(h, p, f(h, p), s)$. Furthermore, consider the strategies where the worker accepts any offer $(w, s)$ such that $\tilde{V}(h, p, w, s) \geq \tilde{V}\left(h, p, w_{f}, s(h, p)\right)$ and rejects any offer such that $\tilde{V}(h, p, w, s)<\tilde{V}\left(h, p, w_{f}, s(h, p)\right)$. Similarly, the firm accepts any offer $(w, s)$ such that $\tilde{J}(h, p, w, s) \geq \tilde{J}\left(h, p, w_{e}, s(h, p)\right)$ and rejects any offer such that $\tilde{J}(h, p, w, s)<\tilde{J}\left(h, p, w_{e}, s(h, p)\right)$.

By definition the firm's payoff satisfies $\tilde{J}(h, p, w, s)=\tilde{V}(h, p, f(h, p), s)-\tilde{V}(h, p, w, s)$. Hence, a firm accepts any offer such that

$$
\tilde{V}(h, p, w, s) \leq \tilde{V}\left(h, p, w_{e}, s(h, p)\right)-\tilde{V}(h, p, f(h, p), s(h, p))+\tilde{V}(h, p, f(h, p), s) .
$$

It is seen that the right hand side of the firm acceptance condition (57) is maximized for $s=s(h, p)$ and does not depend on $w$. Hence, any worker deviation $s_{e}^{\prime} \neq s_{e}=s(h, p)$ that will be accepted by the firm must result in a worker payoff $\tilde{V}\left(h, p, w, s_{e}^{\prime}\right)<\tilde{V}\left(h, p, w_{e}, s(h, p)\right)$, for any $w$, which is not profitable.

A similar argument can be made that the firm will not want to deviate from $s_{f}=s(h, p)$. The worker will accept any offer such that,

$$
\tilde{J}(h, p, w, s) \leq \tilde{V}(h, p, f(h, p), s)-\tilde{V}\left(h, p, w_{f}, s(h, p)\right) .
$$

It is seen that the right hand side of the worker acceptance decision (58) is maximized for $s=s(h, p)$ and that it does not depend on $w$. Hence, any firm deviation $s_{f}^{\prime} \neq s_{f}=s(h, p)$ that will be accepted by the worker must result in a firm payoff $\tilde{J}\left(h, p, w, s_{f}^{\prime}\right)<\tilde{J}\left(h, p, w_{f}, s_{f}\right)$, for any $w$, which is not profitable.

It also follows directly from the above acceptance arguments that any strategy that prescribes $s_{e} \neq s(h, p)$ or $s_{f} \neq s(h, p)$ cannot be an equilibrium because a deviation to $s(h, p)$ will be profitable.

Now consider potential deviations in the wage. The worker's payoff $\tilde{V}\left(h, p, w, s_{e}\right)$ is monotonically increasing in $w$. It follows directly from (57) that any worker wage offer deviation $w_{e}^{\prime}$ that will 
be accepted by the firm is such that $w_{e}^{\prime} \leq w_{e}$. This is not profitable. Any other deviation will not be accepted by the firm and is therefore also not profitable. A similar argument applies to possible firm wage offer deviations.

Sub game perfection of the acceptance strategies requires that the worker is indifferent between accepting the firm's offer $\left(w_{f}, s_{f}\right)$ and rejecting it. A similar indifference applies on the firm side. This disciplines the acceptance levels by,

$$
\begin{aligned}
\hat{V}\left(w_{f}\right) & =(1-\Delta)\left[\beta \hat{V}\left(w_{e}\right)+(1-\beta) \hat{V}\left(w_{f}\right)\right]+\Delta V_{0}(h) \\
\hat{J}\left(w_{e}\right) & =(1-\Delta)\left[\beta \hat{J}\left(w_{e}\right)+(1-\beta) \hat{J}\left(w_{f}\right)\right]
\end{aligned}
$$

where $\hat{V}(w)=\tilde{V}(h, p, w, s(h, p))$ and $\hat{J}(w)=\tilde{V}(h, p, w, s(h, p))$. Equations (59) and (60) can be rewritten as,

$$
\begin{aligned}
\beta\left[\hat{V}\left(w_{f}\right)-\hat{V}\left(w_{e}\right)\right] & =\Delta\left[V_{0}(h)-\beta \hat{V}\left(w_{e}\right)-(1-\beta) \hat{V}\left(w_{f}\right)\right] \\
(1-\beta)\left[\hat{J}\left(w_{f}\right)-\hat{J}\left(w_{e}\right)\right] & =\Delta\left[\beta \hat{J}\left(w_{e}\right)+(1-\beta) \hat{J}\left(w_{f}\right)\right] .
\end{aligned}
$$

Taking the limit as $\Delta \rightarrow 0$, equations (59) and (60) imply that $w_{f} \rightarrow w_{e}$. Denote the common limit by $w$. Hence,

$$
\begin{aligned}
\frac{\partial \hat{V}(w)}{\partial w} & =\lim _{\Delta \rightarrow 0} \frac{\hat{V}\left(w_{f}\right)-\hat{V}\left(w_{e}\right)}{w_{f}-w_{e}} \\
\frac{\partial \hat{J}(w)}{\partial w} & =\lim _{\Delta \rightarrow 0} \frac{\hat{J}\left(w_{f}\right)-\hat{J}\left(w_{e}\right)}{w_{f}-w_{e}} .
\end{aligned}
$$

Since changes in $w$ only affect the match surplus split, it follows that $\partial \hat{V}(w) / \partial w=-\partial \hat{J}(w) / \partial w$. Hence, taking the limit $\Delta \rightarrow 0$ in equations (61) and (62) yields,

$$
\begin{aligned}
-\frac{\beta}{1-\beta} & =\frac{V_{0}(h)-\beta \hat{V}(w)-(1-\beta) \hat{V}(w)}{\beta \hat{J}(w)+(1-\beta) \hat{J}(w)} \\
& \Uparrow \\
\hat{V}(w) & =\beta \hat{V}(f(h, p))+(1-\beta) V_{0}(h) .
\end{aligned}
$$

Hence, as the break down probability goes to zero, the outcome of the alternating offers game limits to the outcome of the axiomatic Nash bargaining outcome in equation (54). 


\section{C.2 Employed worker}

Cahuc, Postel-Vinay, and Robin (2006) provide a strategic bargaining foundation for the axiomatic Nash bargaining outcome in equation (56). The outcome is a subgame perfect equilibrium in a game based on firms submitting bids for the worker subject to a worker's option to use the bids as threat points in a subsequent strategic bargaining game. In the game between two employers of types $q$ and $p$, respectively, where $q \leq p$, the higher type firm wins by submitting a contract bid $(w, s(h, p))$ as stated in equation (56). 


\section{References}

Abowd, John M., Francis Kramarz, and David N. Margolis (1999). High wage workers and high wage firms. Econometrica 67, no. 2: 251-334.

Binmore, Ken, Ariel Rubinstein, and Asher Wolinsky (1986). The nash bargaining solution in economic modelling. The RAND Journal of Economics 17, no. 2: 176-188.

Cahuc, Pierre, Fabien Postel-Vinay, and Jean-Marc Robin (2006). Wage bargaining with on-thejob search: Theory and evidence. Econometrica 74, no. 2: 323-64.

Christensen, Bent Jesper, Rasmus Lentz, Dale T. Mortensen, George Neumann, and Axel Werwatz (2005). On the job search and the wage distribution. Journal of Labor Economics 23, no. 1: 31-58.

Dey, Matthew S. and Christopher J. Flinn (2005). An equilibrium model of health insurance provision and wage determination. Econometrica 73 , no. 2: 571-627.

Eeckhout, Jan and Philipp Kircher (2008). Identifying sorting, in theory. University of Pennsylvania Working Paper.

Jolivet, Grégory, Fabien Postel-Vinay, and Jean-Marc Robin (2006). The empirical content of the job search model: Labor mobility and wage distributions in europe and the US. European Economic Review 50, no. 4: 877-907.

Lentz, Rasmus (2007). Sorting in a general equilibrium on-the-job search model. Working paper.

Lise, Jeremy, Costas Meghir, and Jean-Marc Robin (2008). Matching, sorting, and wages. University College London Working Paper.

Melo, Rafael Lopes de (2008). Sorting in the labor market: Theory and measurement. Yale Working Paper.

Nagypál, Éva (2005). On the extent of job-to-job transitions. Working paper.

Postel-Vinay, Fabien and Jean-Marc Robin (2002). Equilibrium wage dispersion with worker and employer heterogeneity. Econometrica 70, no. 6: 2295-2350. 
Rubinstein, Ariel (1982). Perfect equilibrium in a bargaining model. Econometrica 50, no. 1: 97-109.

Shimer, Robert and Lones Smith (2000). Assortative matching and search. Econometrica 68, no. 2: 343-369.

Yamaguchi, Shintaro (2006). Job search, bargaining, and wage dynamics. Working Paper. 